\title{
GROWTH AND MORPHOGENESIS OF SOME MARINE HYDROZOA ACCORDING TO HISTOLOGICAL DATA AND TIME-LAPSE STUDIES
}

\author{
AUTHOR(S): \\ Beloussov, L. V.
}

\section{CITATION:}

Beloussov, L. V.. GROWTH AND MORPHOGENESIS OF SOME MARINE HYDROZOA

ACCORDING TO HISTOLOGICAL DATA AND TIME-LAPSE STUDIES. PUBLICATIONS OF THE SETO MARINE BIOLOGICAL LABORATORY 1973, 20: 315-366

\section{ISSUE DATE:}

1973-12-19

URL:

http://hdl.handle.net/2433/175770

RIGHT: 


\title{
GROWTH AND MORPHOGENESIS OF SOME MARINE HYDROZOA ACCORDING TO HISTOLOGICAL DATA AND TIME-LAPSE STUDIES
}

\author{
L.V. BELOUSSOV \\ Department of Embryology, Moscow University
}

With 32 Text-figures

\begin{abstract}
Factors of embryonic polarization in Clava multicornis and Obelia loveni and cellular mechanisms of growth and morphogenesis of vegetal generation mainly in Obelia loveni and Dynamena pumila were studied. Morphological axis of embryo was found to be not determined irreversibly up to morula stage. Unequal distribution of mitotic divisions was demonstrated to be a main cause of embryo elongation.

No definite relations were registered between shape and/or growth rate of vegetal rudiments and the characteristics of proliferative processes.

Using time-lapse methods, a pulsatory character of growth and shapening was revealed. Growth pulsations are underlined by periodical contractions-extensions of densely packed cells of ecto- and entoderm.

Some modes of behaviour of a system, composed by contractile, densely packed cells, are formulated. A number of normal and experimentally modified morphogenetic processes in Hydrozoa may be regarded as direct consequences of the properties of such systems.
\end{abstract}

\section{Contents}

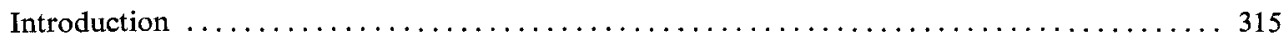

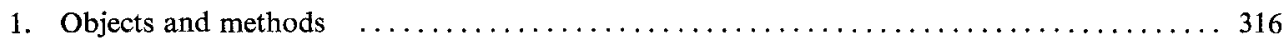

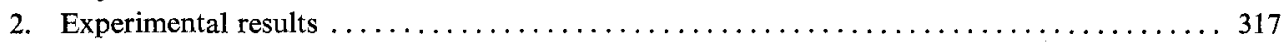

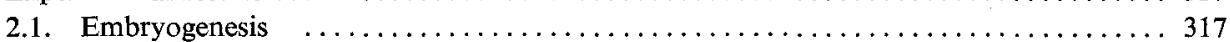

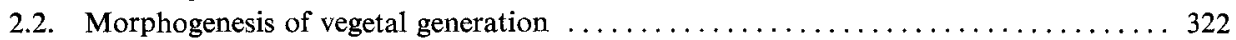

3. General interpretation of hydrozoan morphogenesis $\ldots \ldots \ldots \ldots \ldots \ldots \ldots \ldots \ldots \ldots \ldots$

3.1. Some morphogenetically important types of cell behaviour $\ldots \ldots \ldots \ldots \ldots \ldots \ldots$

3.2. Interpretation of vegetal morphogenesis of Obelia loveni $\ldots \ldots \ldots \ldots \ldots \ldots \ldots \ldots$

3.3. Interpretation of specific properties of vegetal morphogenesis of Dynamena pumila . 360

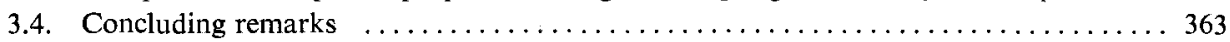

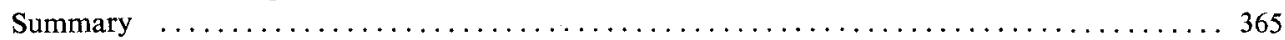

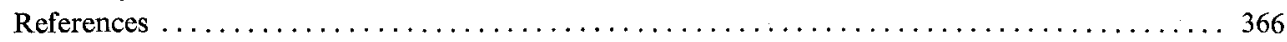

\section{Introduction}

For a long time hydroid polyps (and particularly fresh-water hydra) were used for elaboration of many important morphogenetic problems. One of the most attractive features of these objects seemed to be the simplicity of their structure, which in some cases has been perhaps overestimated. Thus, Hydrozoa were often regarded 
as one-dimensional systems available only for studying the phenomena of polarization and regionalization along one main axis. Really, however, their spatial organization is much more complex. In my opinion, the main attractiveness of these objects (I mean, especially, subcl. Thecaphora) is their detailed three-dimensional geometrical organization which makes them really elegant even if using the most severe aesthetic criteria. ${ }^{1)}$ The rapid development of detailed geometrical pattern from a very simply organized embryo or outgrowth presents in a purified form one of the most intriguing problems of organic development.

In the present paper some results of investigations of hydrozoan morphogenesis by our research group during 1960-1972 are exposed. Its task was to elucidate the cellular mechanisms, determining the specific shape of hydrozoan body. One of the main ideas, establishing in the course of these investigations was, that a small number of simple and monotonously repeated cellular activities are sufficient to realize the whole process of their shapening without employing any special governing (regulative) factors. Such "self-regulating" systems require also a quite restricted number of external stimuli obviously also of a simple nature.

Some moments of embryonic development and the whole course of morphogenesis of vegetal generation (vegetal morphogenesis) of several hydrozoan species were studied.

\section{Objects and Methods}

Some processes of embryonic development of Obelia loveni (Allm.) (Thecaphora) and Clava multicornis (FORSKÅL) (Athecata) were studied. Vegetal morphogenesis was extensively studied in Obelia loveni and Dynamena pumila (L.). Some observations were made in Obelia geniculata (L.), Campanularia integra (MCGILL), Campanulina lacerata (JoHNST.) (all species belong to subcl. Thecaphora; all systematics according to Naumow, 1960).

The samples were collected on the tide lands of the White Sea. Experimental studies and time-lapse filming were performed at the White Sea Biological Station of Moscow University. For visual observations and filming the samples were cultivated in 20-50 ml glass dishes without any special precautions. The following methods were employed:

1.1. Vital staining of intact and dissected embryos by pressing them to small pieces of agar impregnated by Nile-blue sulphate.

1.2. Vital staining of vegetative parts of Obelia loveni by immersing them for 40-60 min into weak solutions of Nile-blue sulphate. Then they were transferred to pure sea water and fixed horizontally. One to 2 hours later the staining became granular. The granules were localized in ectodermal cells exclusively. The movement of several (up to 4) granules was continuously traced during 2-3 hours with the use of

1) "Obelia is an object of great beauty and some delicacy" (F. HАMMET). 
water-immersion objective $\times 40$.

1.3. Time lapse films. Several periods of stem growth and hydranth formation in Obelia loveni and Dynamena pumila were registered on $35 \mathrm{~mm}$ film. Exposure intervals were $1,5,10,30,120 \mathrm{sec}$. The duration of continuous filming was up to 12 hours. The "Convas" camera was used, combined with microscope MBI-3. The microscope objectives were $\times 3, \times 8, \times 10, \times 40$ (water immersion). The samples were immersed in a $20 \mathrm{ml}$ glass dish, being attached to its bottom by an adhesive tape. The temperature varied from $15^{\circ} \mathrm{C}$ to $20^{\circ} \mathrm{C}$.

1.4. For histological purposes embryos and parts of colonies were fixed in a Bouin solution and embedded in paraffin wax or paraffin-celloidin; 8-12 $\mu$ sections were prepared. The slides were stained with HeIDENHAIN's iron haematoxylin.

To measure concentration (density) of nuclei a number of cell nuclei per $400 \mu^{2}$ square was counted at several median sections through a given region and an average value was calculated.

1.5. Radioautography. In the present paper only the results, obtained by thymidine method, are described (about the incorporation of other precursors see Belousov and Ostroumova, 1969). Only planulae and primary hydranths, but not any parts of adult colonies were found to be permeable for ${ }_{3} \mathrm{H}$-thymidine. The latter was used in sea-water solution, concentration $2 \mu \mathrm{C} / \mathrm{ml}$. The samples were incubated during $40 \mathrm{~min}$. Radioautographs were prepared by routine methods. Period of exposure was 3 weeks.

\section{Experimental Results}

2.1. EMBRYOGENESIS.

2.1.1. Factors Determining the Morphological Polarity of Obelia loveni and Clava multicornis Embryos.

An exhaustive review of morphogenesis and, particularly, of polarization processes in embryonic development of Hydrozoa was recently made by MERGNer (1971). He came to the conclusion that, inspite of great regulatory capacities of embryos their polarity is stabilized quite early (as a rule, during oogenesis), and that the anteroposterior axis of planula (and, consequently, of a primary hydranth) inevitably coincides with the animo-vegetal axis of an oocyte.

This point of view bears close relations with CHILD's conception of exogeneous aeration or nutrition gradients strictly determining the metabolic axis of oocyte and, thus, the antero-posterior axis of planula and primary hydranth.

One may hardly doubt that such situation is true for the great majority of Coelenterata and, particularly, of Hydrozoa. However, we shall demonstrate that in several cases some deviations from this scheme are taking place and that the polarity of freeswimming planula and, all the more, of a fixed hydranth, is not always irreversibly determined at the earliest stages of their development. 
A
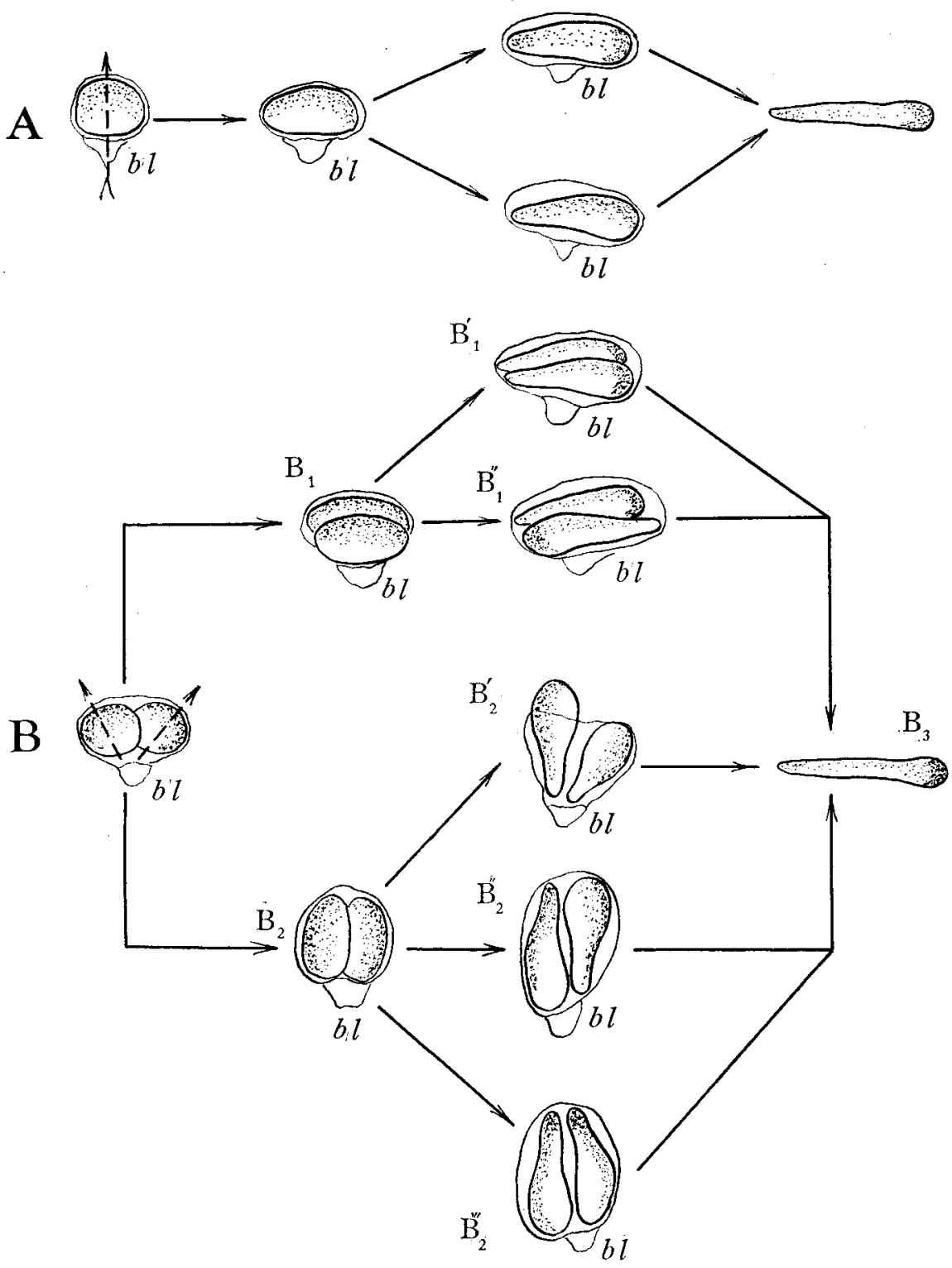

Fig. 1. Different kinds of orientation of the vectors of metabolic gradients (indicated by the density of stippling) and of morphological axes (a wider end corresponds to the anterior one) in relation to each other and to the blastostyle (bl) in Clava multicornis embryos. A-solitary Clava embryo; B-two Clava embryos in one sporosac. A and $\mathrm{B}_{1}$-embryos elongate perpendicularly to the blastostyle-external surface line. $B_{1}^{\prime}-$ the homologous poles of the both embryos are oriented to the same side, $B_{1}{ }^{\prime \prime}$, to the opposite sides. $B_{2}-$ elongation parallel to blastostyle-external surface line. $\mathbf{B}_{\mathbf{2}}{ }^{\prime} \mathbf{B}_{2}{ }^{\prime \prime}$ - -homologous poles in both embryos are oriented similarly, but in $\mathbf{B}_{2}{ }^{\prime}$ the anterior pole, while in $\mathbf{B}_{2}{ }^{\prime \prime \prime}$ the posterior one is exposed to the external surface. $\mathrm{B}_{2}{ }^{\prime \prime}$-the orientation of the homologous poles of both embryos is reversed. $B_{3}-$ completed planula, having an identical morphological and gradient structure inspite of the mode of the previous embryo orientation. Arrows in A and B indicate the directions of the primary gradients from blastostyle to external surface of eggs. (From Belousov and Ostroumova, 1969, modified). 
Two sets of facts are to be pointed out in this respect.

2.1.1.1. Morphological Polarization in Normal Development of Clava multicornis (See in Details Belousov and Ostroumova, 1969).

Eggs and embryos of $C$. multicornis are developed in sporosacs, each containing one or two eggs. According to position of germinal vesicle, an external (removed from blastostyle) part of an egg corresponds to the animal one, whereas the internal part (adjacent to blastostyle) is to be regarded as vegetal. Local vital staining of the external part of egg surface has demonstrated that no rotations of egg inside sporosac take place during its early development.

At the oocyte and early embryonic stages the pronounced metabolic gradients (so-called primary gradients) can be revealed by various methods. Their direction coincides, generally, with the animal-vegetal (AV) direction or slightly deviates from it. However, the direction of subsequent embryo elongation and (or) the direction of the vector of morphological polarization (i.e. antero-posterior direction of planula) in a number of cases do not coincide with that of primary gradients and, respectively, of an initial oocyte polarity. The main observed variants are presented in Fig. 1. One can see, that if a sporosac contains a single egg, the direction of its elongation is as a rule perpendicular to $\mathrm{AV}$ and to the vector of primary gradient (Fig. 1,A). If sporosac contains two eggs, the both are often polarized in the opposite directions: that is, in one of them the anterior pole is developed from the external pole of egg (correspondingly, from the animal pole and from the highest point of the primary metabolic gradient), whereas in the adjacent embryo the same pole gives rise to the posterior part of larva (Fig. 1, $\mathrm{B}^{\prime \prime}{ }_{2}$ ). Moreover, in free-swimming larvae the primary gradients which do not coincide with the vectors of morphological polarization, disappear in the course of development and the metabolic activities are redistributed, coming into complete correspondence with the morphological polarity: the anterior pole of planula, whatever be its origin, inevitably becomes the higher point of metabolic activity (Fig. 1, $\mathrm{B}_{3}$ ).

These data lead to the conclusion, that the primary polarity can be "overcomed" and, thus, in the course of embryogenesis some "secondary" powerful polarizing factors play a role. Its nature is partly revealed in the following experiments.

2.1.1.2. Experimental Analysis of Polarization in Obelia loveni Embryos.

2.1.1.2.1. At What Stage is the Polarity Irreversibly Determined?

Already morulae of $O$. loven $i$ are slightly elongated in certain direction. So far as it could be traced the direction of elongation is not changed during the normal subsequent development. Does that mean, however, that the morphological axis is irreversibly determined not later than the morula stage and cannot be later reoriented by any experimental procedures? To test this possibility, the embryos of different stages were dissected transversely to their long axis and the dissected surface was marked by vital dye (Fig. 2). If the operation was made at the morula stage (Fig. 2 , A), the stained region was situated in all cases on the lateral side of regenerated 


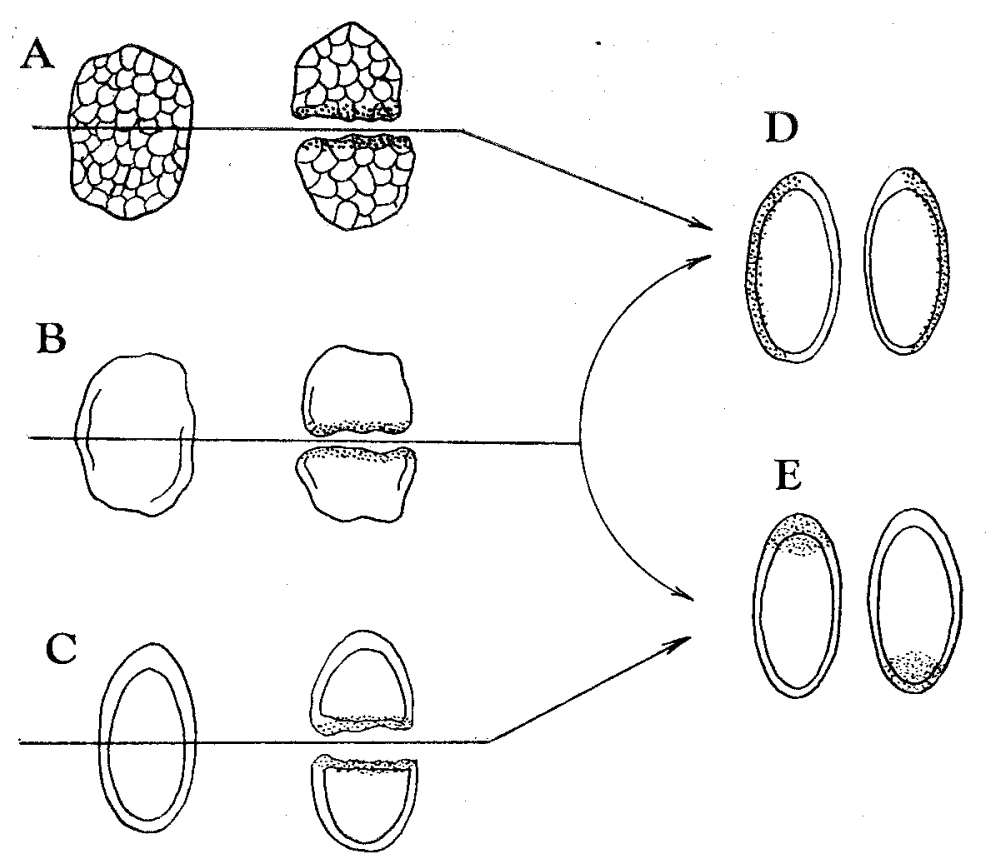

Fig. 2. Dissections of morulae (A), delaminating embryos (B) and planulae (C) of Obelia loveni. D, E-results of operations. Note the position of vitally stained (punctured) areas. (From Ostroumova and Belousov, 1971).

planula (Fig. 2, D). It means that the regenerated larva was elongated in the direction, perpendicular to that of the morula and, respectively, of the intact embryo. Same operations, performed after the beginning of delamination (Fig. 2, B), led to two kinds of results: the stained region was situated either on the lateral surface of planula (Fig. 2, D) or at one of its poles (Fig. 2, E). In similar experiments at parenchymula stage (complete delamination, Fig. 2, C) the stained region was in all cases situated at the polar region of planulae (Fig. 2, E). Therefore, up to delamination stage the direction of elongation can be altered after dissection; its irreversible determination takes place only after the delamination has been completed.

2.1.1.2.2. Mechanical Deformations as a Polarizing Factor.

Sporosacs of $O$. loveni were stretched or pressed by glass needles and fixed in these positions during two days (from morula stage up to hatching from sporosac). In these experiments the embryos were stretched either parallel or perpendicularly to the axis of blastostyle of a given sporosac (Fig. 3, A, B). All embryos under study ( 40 embryos from 20 sporosacs in the first experiment and 20 embryos from 10 sporosacs in the second experiment) transformed to planulae which were elongated in the direction of the artificial mechanical stretching. No rotations of embryos inside sporosacs took place. At the same time, in normal development about $63 \%$ of embryos became elongated parallel, $27 \%$ perpendicularly and $10 \%$ obliquely to blastostyle axis. Thus, 


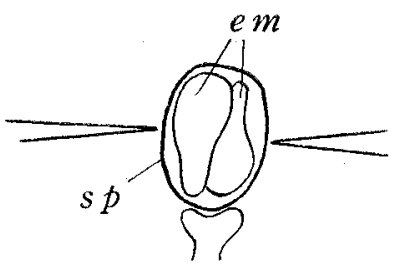

A

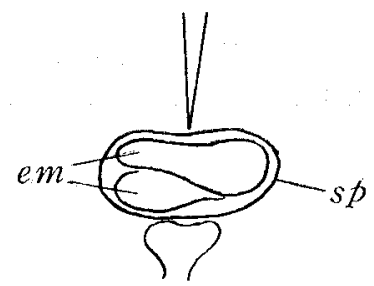

$\mathrm{B}$

Fig. 3. Positions of $O$. loveni embryos (em) in sporosacs (sp) while pressed by glass needles. The embryos are arranged either parallel (A) or perpendicularly (B) to blastostyle axis. (From Ostroumova and BelouSov, 1971).

the experimental results significantly differ from the normal situation: a considerable part of embryos was forced to elongate in an abnormal direction, which was stabilized and retained even after hatching.

So far as normally the embryos in sporosacs are also closely packed, one may believe that the mechanical pressure plays a polarizing role in the normal conditions, too. That can be true not only for $O$. loveni, but also for $C$. multicornis developing in similar mechanical conditions. For example, the above cases of the opposite morphological polarization of the adjacent embryos in $C$. multicornis sporosacs (Fig. 1, B") hardly may be explained by the assumption of predetermined polarity but may be regarded as natural consequences of the "best packing" principle: so far as the anterior regions are wider than the posterior ones the opposite polarization of adjacent embryos is much more probable than their parallel polarization.

If attempting to coordinate these data with those of (1.1.2.1.), one may speculate that not the mechanical pressure itself, but only its immediate result, namely, the forced deformation (elongation) of embryo plays a leading polarizing role. The matter is that the transverse dissection of slightly elongated morula completely changes its proportions: the initially transverse direction becomes parallel to the long axis of regenerate, and vice versa. At the same time, the dissection of fairly elongated larva does not evidently lead to any principal alterations of its proportions. A simple principle of "self-increasing" elongation in a direction, determining by any slightly deforming factor seems to unite the above data as well as some others presented below.

One cannot, certainly, forget that coelenterate embryos can develop and polarize perfectly well also outside sporosacs, without any deforming factors. Do the above mechanisms play any role in these cases? One may remember here that due to the anarchic cleavage, hydrozoan embryos in no cases become regularly spherical or, at least, isodiametric bodies. Slight deviations in proportions are always taking place and therefore the initial conditions for the principle of "self-increasing" elongation are practically always fulfilled. It is probable, however, that in these cases the primary, 
oocyte polarization plays a greater role. Nevertheless, as it will be demonstrated later, the phenomenon of increasing of slight preceding deformations seems to be one of the general principles for many morphogenetic processes of Hydrozoa and, possibly, not only for them.

2.1.2. Cellular Processes, Determining the Elongation of O. loveni Embryos.

The role of cell multiplication in embryo elongation was studied by ${ }_{3} \mathrm{H}$-thymidine and classical histological methods. The total nuclei concentration (Fig. 4,B) and the concentration of labelled nuclei in different regions of the ectoderm of embryos and planulae (Fig. 4,C) have been compared with the degree of elongation at different stages of development (Fig. 4,A). One can see that already at the morula stage a percent of labelled nuclei at the lateral side of embryo (Fig. 4C, 3) slightly exceeds the same at its poles (Fig. 4C, 4); up from parenchymula stage the difference becomes much more pronounced (Fig. 4,C, compare 3 with 5,6). At the same time, the differences in the total nuclei concentration in the corresponding regions are much less pronounced (Fig. 4,B, compare 3 and 4, or 3 and 5,6). It is clear therefore that the excess of proliferating cells at the lateral sides of embryo (in comparison with that at the polar regions) goes to the embryo elongation along the polar axis ${ }^{2}$. (In the case of significant regional variations in total nuclei concentration the relations between the concentration of labelled nuclei and the elongation of a given region would obviously be not so definite.)

\subsection{Morphogenesis of Vegetal Generation.}

2.2.1. The External Picture of Development of Vegetal Generation of Obelia loveni and Dynamena pumila.

The complexity and regularity of three-dimensional organization of hydroid polyps is strongly expressed in the course of their vegetal morphogenesis. Its main features are as follows.

2.2.1.1. Obelia loveni and $O$. geniculata. (Fig. 5). The branching of the colonies is sympodial.3) The branches of both species are bent, in $O$. loveni the bending being more pronounced than in $O$. loveni. The new stems are initiated either just below the growing tip of the maternal stems, or on the proximal parts of the colony. In the first case the new (daughter) stems are formed always at the convex side of the maternal ones (Fig. 5, A,d,s.) and grow at the same plane. Just after their initiation the daughter stems grow parallel to the maternal ones (Fig. 5,B, d.s.), but later their tips deviate lateralwards (Fig. 5,C,D, d.s.). In the proximal regions new stems are initiated in the axiles of the old ones. The plane of bending of the first ones is in no way correlated with the plane of bending of the latter.

As stem growth proceeds, several circular grooves are formed one after another

2) It must be remembered that planula ectoderm remains approximately monolayered during the whole development.

3) This type of branching is characterized by a replacement of an old growth point by a new after the formation of each new outgrowth; every growth point arises proximally to the old one. 

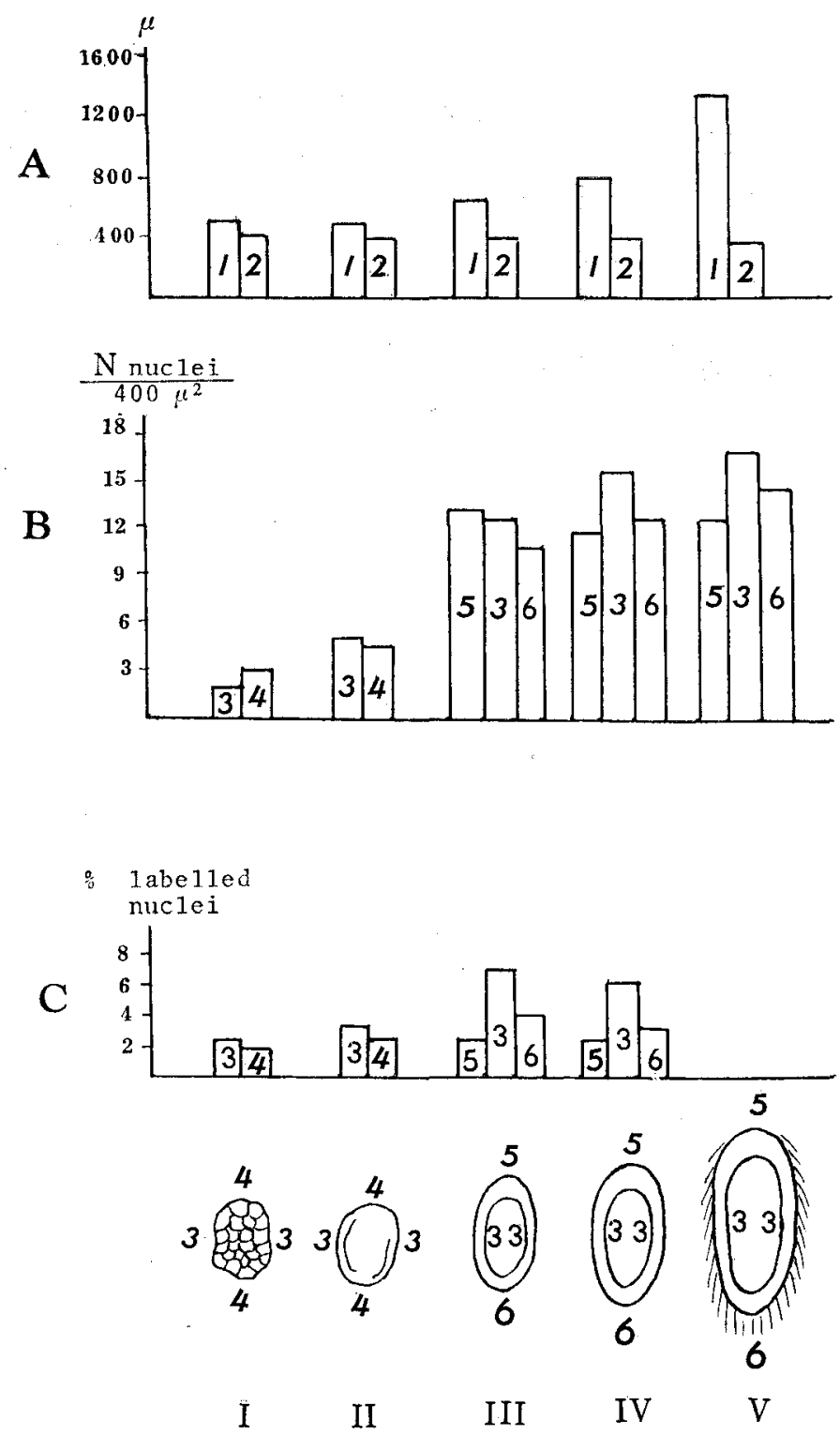

Fig. 4. Evolution of body proportions (A), of total ectodermal nuclei concentration (B) and of ${ }_{3} \mathrm{H}$-thymidine labelled ectodermal nuclei concentration $(\mathrm{C})$ at successive stages (I-V) of C. multicornis development. 1-length. 2-width of embryo in $\mu$. 3-total (B) or labelled (C) nuclei concentration in lateral body wall. 4, 5, 6,-the same correspondingly at the as yet undifferentiated pole of early embryo, at the anterior and posterior pole of planula. Below are sketches of the corresponding developmental stages with the same indications (From OsTroumova and Belousov, 1971). 


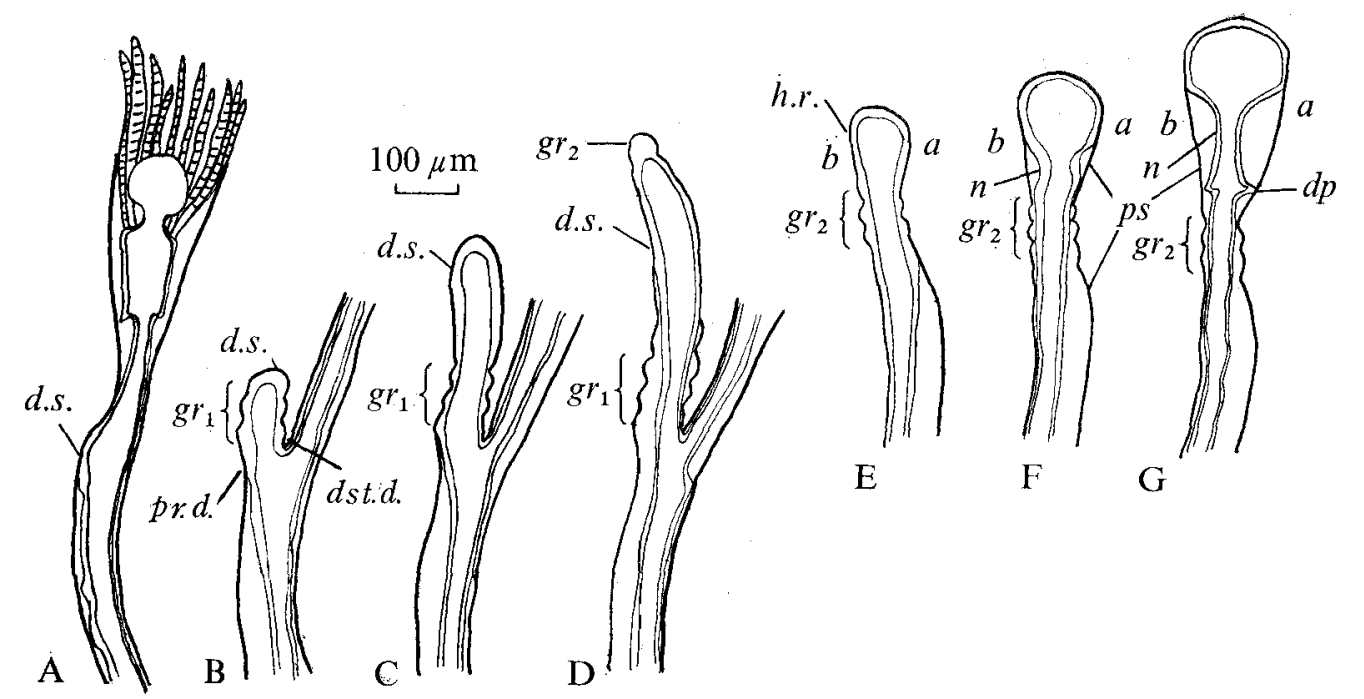

Fig. 5. A-G. Successive stages of development of stem and hydranth in Obelia loveni (pictures from time-lapse film). (From Belousov et al., 1972, modified).

d.s.- daughter stem; $\mathrm{gr}_{1}$ - first series of grooves; $\mathrm{gr}_{2}-$ second series of grooves; h.r.--hydranth rudiment; n-hydranths "neck"; dp-diaphragm, a-side of a hydranth, adjacent to maternal stem; ps--perisarc; pr.d.--proximal depression, dst.d.-distal depression (see p.358).

at some distance from their tips (Fig. 5, B,C, $\mathrm{gr}_{1}$ ), those fixed by chitinous perisarc. In general about 3-4 such grooves are formed (dividing a stem to several "segments"), and then a period of "smooth" growth takes place, being in its turn succeeded by a new period of groove formation (Fig. 5, D-G, $\mathrm{gr}_{2}$ ). Later the part of the stem, located distally from the last groove, expands and elongates, thus forming a rudiment of a hydranth (Fig. 5, E, h.r.). The proximal part of the rudiment is constricted, forming a hydranth's "neck" (Fig. 5, F,G,n). A thin cellular plate, a diaphragm, develops proximally to the neck (Fig. 5, G, dp). The most expanded part of the rudiment, situated distally to its neck, later splits to a series of columnar tentacle rudiments, whereas its roof transforms to a hypostome. A hydranth becomes slightly asymmetrical in the plane of the stem bending: the side of a hydranth, adjacent to the maternal stem (Fig. 5, E-G, a) is slightly more convex than the opposite side. At the same time the hydranth is completely symmetrical in the plane, perpendicular to that of stem bending.

2.2.1.2. Dynamena pumila (Fig. 6). The branching is monopodial. ${ }^{4}$ The vertical branches are composed of a series of storeys, each including a pair of identical lateral (LR) and a central rudiment (CR) (Fig. 6,A). The LRs are bent distally (Fig. 6, B-D) and later transform to hydranths, whereas the CR remains undifferentiated and grows further. At first its tip is narrowed, but later it expands and is transformed

4) This type of branching is characterized by a prolonged action of a single growth point which is situated at the distal pole of the growing stem. 


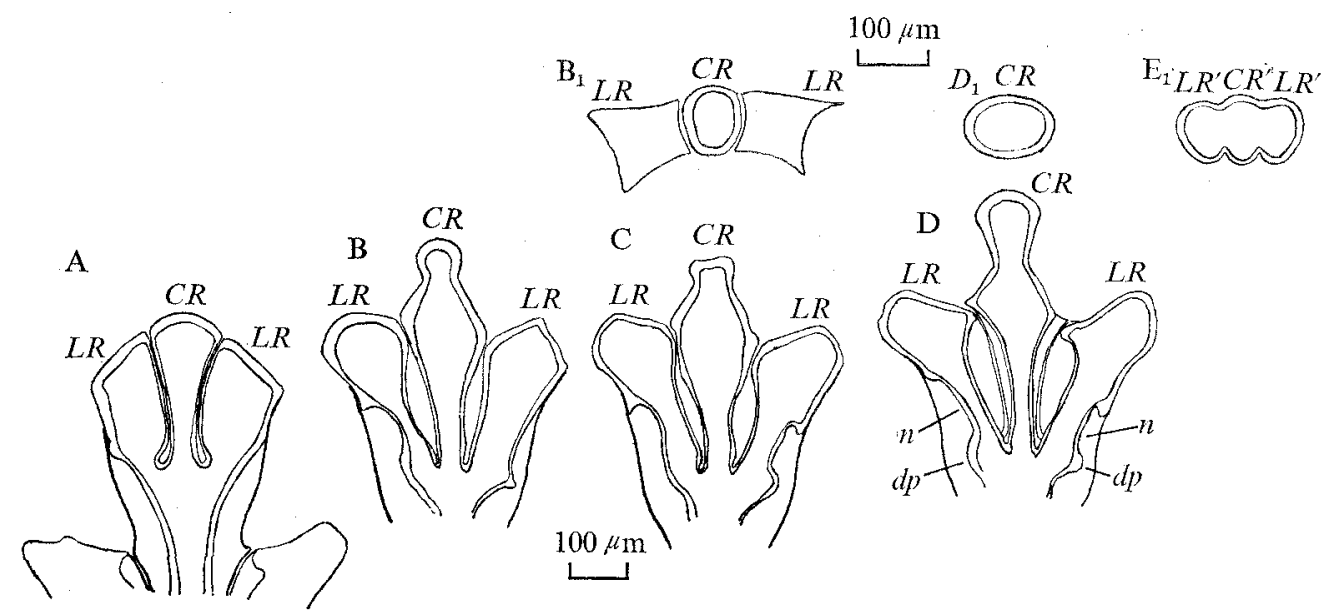

Fig. 6. A-E. Successive stages of development of growing tip in Dynamena pumila (pictures from time-lapse film). A-D-side view, $B_{1}-E_{1}$-top view. CR-central rudiment, LR-lateral rudiment. $\mathrm{B}, \mathrm{C}$-the opposite phases (extension and contraction) of the same growth pulse.

to a spherical (Fig. 6,B) and then to a triangular (Fig. 6, D) rudiment. The plane of its expansion completely coincides with that of preceding $\mathrm{CR}$. Thus the whole colony is flattened in a single plane (Fig. 6, $B_{1}, D_{1}, E$ ). After expansion, each new $C R$ is splitted by two vertical furrows to three rudiments (Fig. 6,E, $\mathrm{LR}^{1}, \mathrm{CR}^{1}$ ), the lateral ones being again transformed to hydranths, whereas the central one growing further. Similar to Obelia hydranths, the LRs are subdivided into a diaphragm, a constricted proximal part and an expanded distal part (Fig. 6,D,dp.n).

The following general features of the described morphogenetic processes are to be underlined: in respect to the directions of their growth, the above mentioned rudiments are, as a rule, either asymmetrical (Obelia) or anisotropical (Dynamena). The plane of anisotropy or asymmetry remains constant for a considerable part of colony.

2.2.2. Morphogenetic Cellular Processes during Vegetal Development according to Histological Data.

2.2.2.1. Some Notes on Cell Structure.

Only those details of histological structure, which are of direct morphogenetic importance, will be described here.

A body of hydroid (usually designed as coenosarc) consists of two cell layers (ectoand entoderm) which do not strictly adhere each other. From time to time a split between the both can appear. The both layers are composed mainly of myoepithelial cells. There are marked differences between the internal structure of ecto- and entodermal myoepithelial cells. While the entodermal cells resemble those of common epithelia, the ectodermal cells look as bundles of fine tonofibrills.

Old investigators believed tonofibrills to be passive, purely supporting structures. Recently, however, a number of data are obtained in favour of their contractile activity, 
which is regarded as a cause of alterations of cell shape (HALE, 1960). Our own evidences, supporting this point of view, will be presented later. There are also some indirect evidences of the presence of similar fibrillar structures in entodermal cells as well; however, they seem to be less active. Besides this type of contractile structures, oriented along cell axes, there exists a net of myofibrills situated in the plane of basal membrane (b.m.) and composed by fibrillar outgrowths of ecto- and entodermal cells. It is the most effective contractile system of Hydrozoa. However, it seems to exist no myofibrills in the tip regions of growing rudiments, i.e. in the areas of the most active morphogenesis (Hale, 1960). They appear only at some distance below the tip, in so-called "contractile zone" and are particularly well developed in adult hydranths.

The ectodermal cells seem to be loosely connected one another. They can as well shift to some extent towards and away from the b.m. keeping however (at least in the majority of cases) filamentous contacts with it. At the same time they are strictly fixed at the common surface (obviously, elastic) membrane of ectoderm, which may be called "plasmalemma". The latter is to be distinguished from hydrotheca, or perisarc -a chitinous layer, secreted by special "cellules glandulaires excrétrices" (described by BILLARD, 1904) and deposited at the external surface of plasmalemma in the tip region.

Newly deposited perisarc of tip regions is fairly soft and does not prevent a growing rudiment to "push" it outwards, resisting at the same time to any attempt of inwards shifting (what can be due, perhaps, to its "crush-resistance" arch shape). Perisarc of slightly more proximal regions is already completely rigid. It remains fixed even after the contraction of the corresponding area of coenosarc (e.g., during the formation of the hydranth "neck"). Thus it can serve as a suitable point of reference.

Besides myoepithelial and glandular cells a number of interstitial (i-) cells always occur in the areas of the both layers, adjacent to b.m. One can trace several stages of

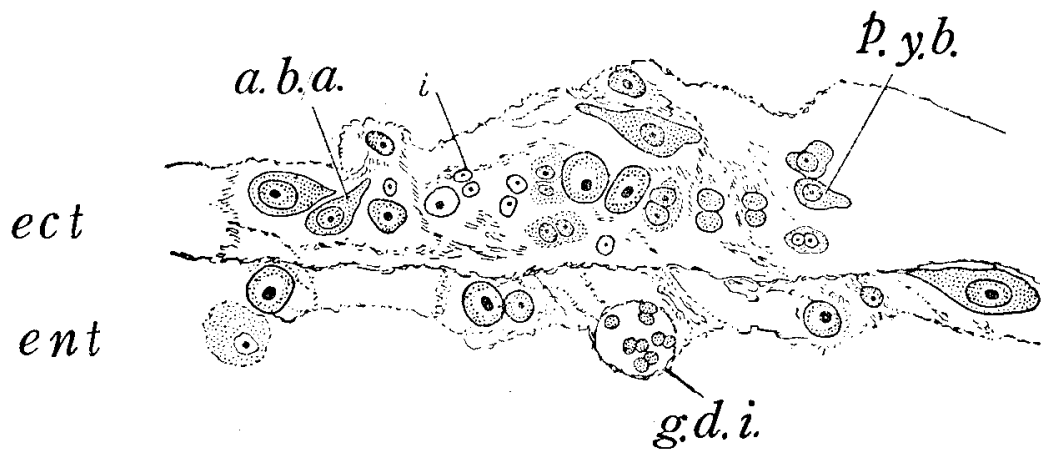

Fig. 7. Structure of a fragment of lateral wall of developing Campanularia integra hydranth. Several stages of differentiation of $\mathrm{i}$-cells are presented. ect- ectoderm, ent-entoderm. $\mathrm{i}$-pair of dividing $\mathrm{i}$ - cell nuclei, p.y.b.-pair of young basophylic cells, a.b.a._adult basophylic amoeboids, capable to migrate and differentiate into other cell type. g.d.i.group of dead undifferentiated i-cells with pycnotic nuclei. Note the anarchic and symplast-like structure of the both cell layers. (From Belousov, 1963). 
their life cycle: a stage of dense nuclear "packets", almost free of cytoplasm, a stage of amoeboid cells with a basophilic cytoplasm (Fig. 7) and a stage of differentiated cells (myoepithelial, cnidoblasts, etc.).

2.2.2.2. Role of Cell Proliferation in Growth and Morphogenesis of Studied Species.

To what extent geometrical regularity of hydrozoan morphogenesis is determined by localization, regional distribution and relative amount of dividing cells and orientation of their mitotic axis?

Our own data (Belousov, 1961b, 1963) agree with those of other authors (Hale, 1964; Crowell, Wyttenbach, Suddith, 1965; Filatcheva, 1966; Campbell 1967); the general conclusion is that there is no definite relation between the above characteristics of proliferative processes and the shape and/or dimensions of a rudiment.

2.2.2.2.1. Localization of Proliferative Zones.

According to histological and radioautographical data, the ectoderm of growing

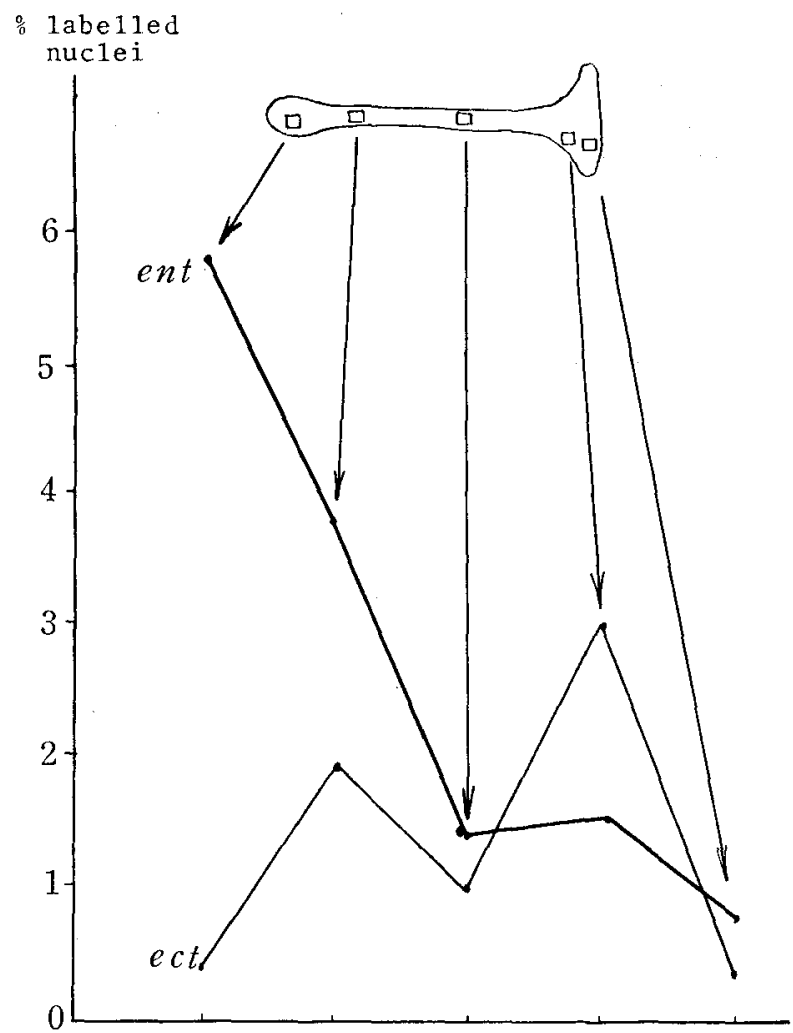

Fig. 8. Regional distribution of concentrations of ${ }_{3} \mathrm{H}$-thymidine labelled nuclei in ecto-(ect) and entoderm (ent) of primary $O$. loveni hydranth. Squares of countings are indicated. 
tips of Obelia and Dynamena stems is almost free of proliferating cells. As a rule, ectodermal proliferative zones are localized proximally, near the base of a given stem (Fig. 8, ect.). Therefore, during the whole period of stem growth its tip is composed of the same ectodermal cells. Periodical alterations of its shape (e.g., formation of successive "segments" in Obelia; see 2.2.1.1.) cannot be determined, at least directly, by proliferative processes.

In the entoderm, on the contrary, the dividing and ${ }_{3} \mathrm{H}$-thymidine incorporating cells are situated throughout the whole outgrowth with the marked disto-proximal gradient of density (Fig. 8, ent).

With the initiation of hydranth development, the loci of proliferating cells (obviously, mainly i-cells) appear in the ectoderm of its lateral walls (Fig. 7). Proliferating
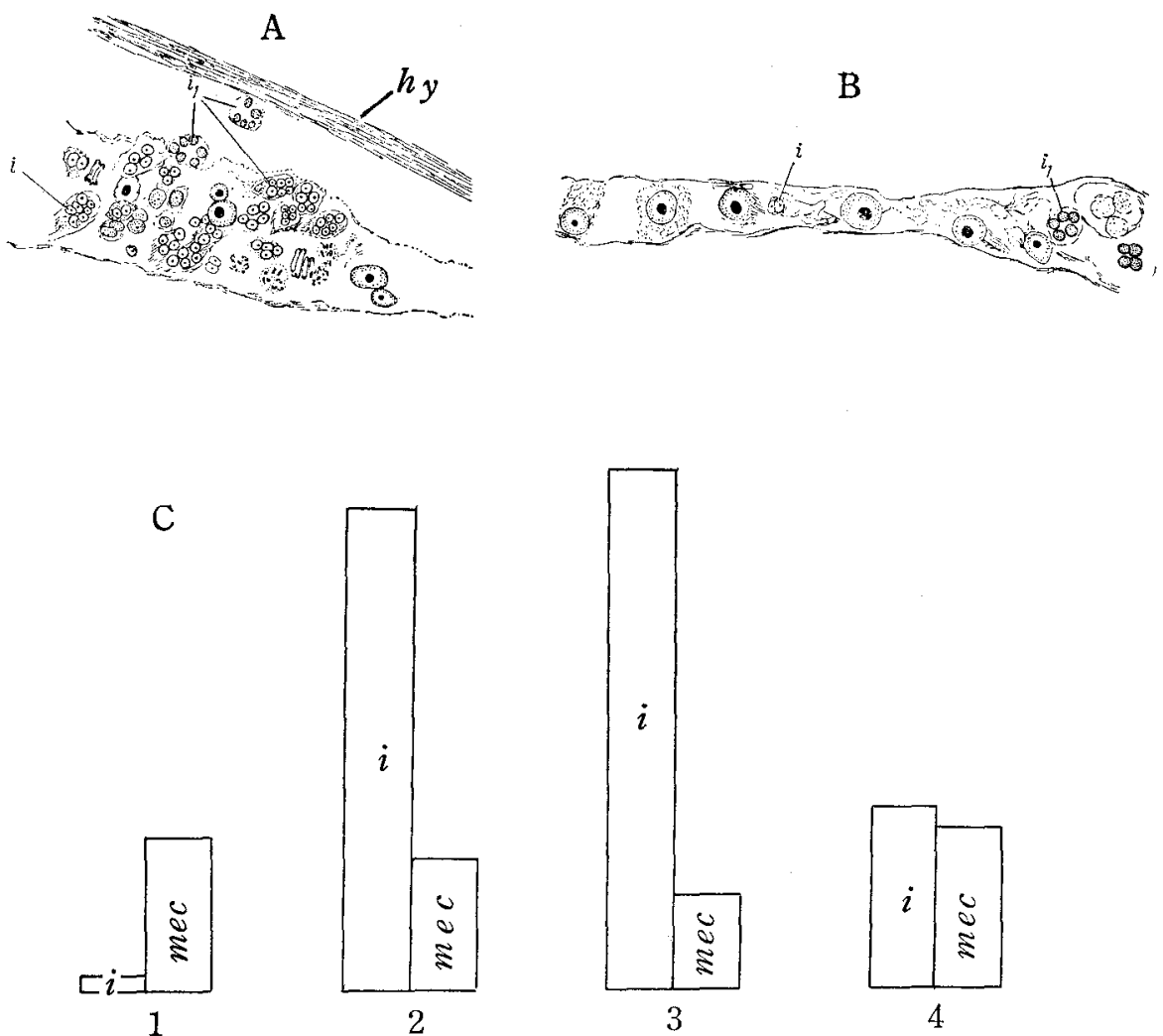

Fig. 9. Two opposite phases of fluctuations in i-cell concentration in the ectoderm of lateral wall of Campanularia integra hydranth. A-maximal concentration of proliferating i-cells (i). Note the packets of dead $i$-cells $\left(i_{1}\right)$ near the periphery of cell layer and under the hydrotheca (hy). B-minimal concentration of $\mathbf{i}$-cells. Almost only large differentiated nuclei are presented. C-graphics of fluctuations in i-cell concentration. $\mathrm{i}$-average concentrations of $\mathrm{i}$-cells in four different samples (1-4). mec-- average concentrations of myoepithelial cells in the same samples. The latter values are much more constant than the first ones. (A, B from Belousov, 1963). 
cells are distributed throughout the whole rudiment in quite irregular manner and are in no case predominantly concentrated in the sites of the most pronounced evaginations of hydranth wall.

2.2.2.2.2. Amount of Proliferating Cells and Growth of the Rudiments.

Are there any definite relations between the increase in cell number and in dimensions of rudiment during the same period? If it were the case, there would be no considerable alterations in cell concentration during the whole growth period (what is true for planula elongation; see 1.2.). In vegetal hydrozoan morphogenesis quite the opposite takes place: in many cases, especially in Campanularia integra and Campanulina lacerata, extremely great fluctuations of cell concentration are observed, being a result of "epidemical" character of multiplication and, then, of death of $\mathrm{i}$-cells (Fig. 9,A,B). At the same time, concentration of adult myoepithelial cells is much more constant (Fig. 9,C; compare $\mathrm{i}$ and $\mathrm{mc}$ ). An impression arises that a certain "barrier" exists between the proliferative and differentiating capacity of cells. Whereas the proliferative activity is obviously almost undetermined and bearing no definite relations with the rate of growth of the whole rudiment, the stimuli for cell differentiation seem to be much more coordinated with the general course of morphogenesis.

Being the extreme examples of discrepancy between the rate of cell proliferation and the utilization of the arising cells in growth and shaping processes, these phenomena possess at the same time some parallels in the development of other species as well. An

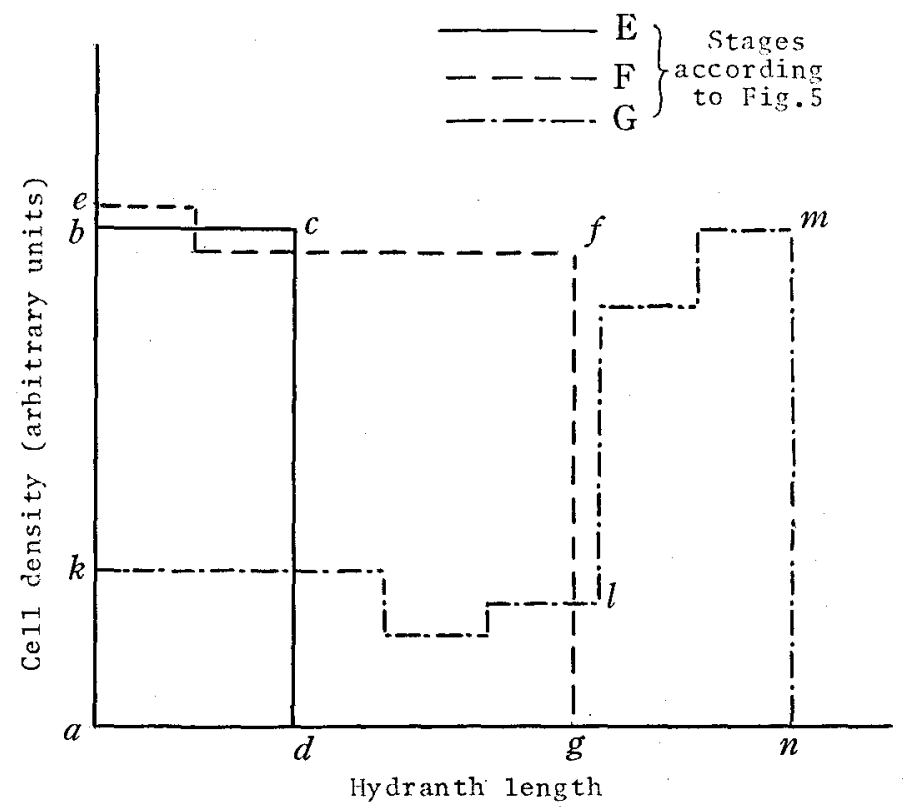

Fig. 10. Distribution of ectodermal cell density along the wall of $O$. loven $i$ hydranth at three successive stages of its development (corresponding to E, F, G in Fig. 5). (From Belousov, 1961b). 
"epidemical" death of young i-cells is observed in proliferative zones of $D$. pumila (FIlATCHEVA, 1966). In O. loveni no signs of "superintensitive" cell proliferation and cell death are noted, but here as well considerable variations in cell concentration are registered (Fig. 10). At the first period of hydranth growth cell concentration in all its regions is approximately the same (abcd, aefg, Fig. 10). Later on a considerable drop of cell concentration in the proximal (elongating) part takes place (KI, compare with ef). Between the two latest stages the total cell number in the whole rudiment remains approximately the same (square aklmn is approximately equal to aefg).

2.2.2.2.3. Orientation of Mitotic Axes.

It is clear already from Fig. 7 that the orientation of pairs of dividing i-cells is completely chaotic. The similar conclusion can be derived from statistical data (Fig. 11).
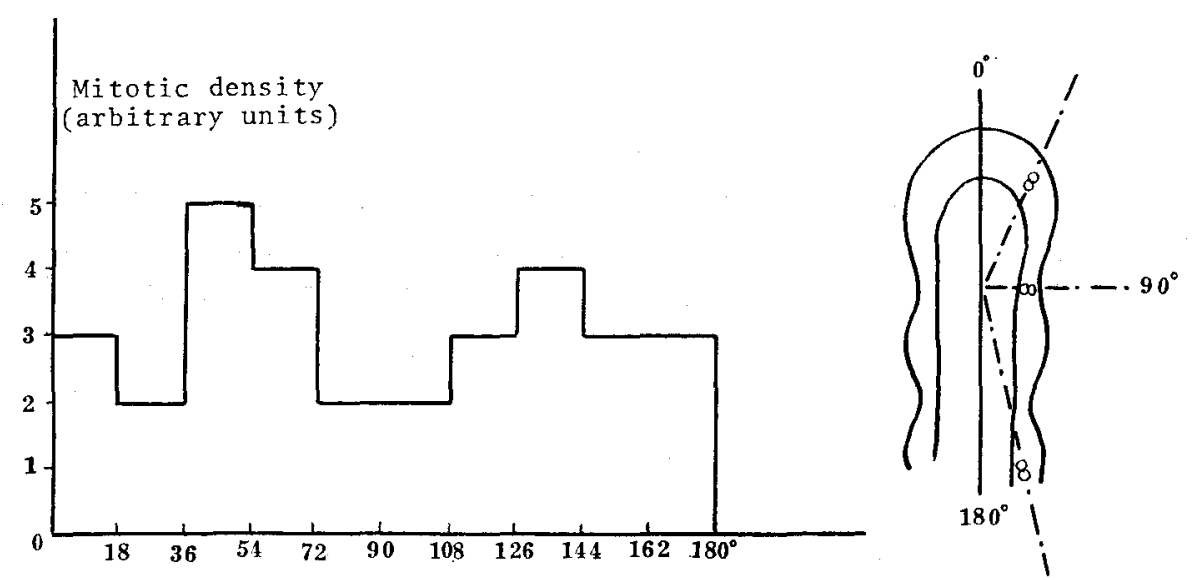

Fig. 11. Distribution of different angles of orientation of just divided i-cell pairs in respect to the axis of straightly growing $O$. loveni stem. Abscissa - angle of orientation, ordinate-number of cell pairs. $0-180^{\circ}$ corresponds to disto-proximal direction. (From Belousov 1961b, modified).

In summarising, one may stress a very low degree of regulation of all studied parameters of proliferative processes. A precise shaping, characteristic for described species, undoubtedly cannot be determined by these processes in any direct manner. Our attention is to be focused therefore to the processes of cell migrations and cell reorientations, which obviously must play a more direct morphogenetic role.

2.2.2.3. Cell Migrations and Reorientations in Normal Development of $O$. loveni and D. pumila.

The most adequate information about cell migration and reorientation is obtained by cinematographic methods. However, cell migrations can be observed as well visually in vitally stained $O$. loven $i$ outgrowths. As it has been already mentioned (1.2), vital dye is concentrated in separate granules, localized in ectodermal cells. One can trace under water-immersion objective the movement of these granules. They 
migrate distalwards at the rate of $30-90 \mu /$ hour, that is comparable with the rate of growth of the whole stem. A certain degree of asynchrony was registered in the migration of granules in the opposite stem walls (for details, see BeLousov, 1961a).

By routine histological methods regular and pronounced differences in orientation of myoepithelial ectodermal cells at different stages of development can be observed. Due to cinematography, it became clear that histologically registered cell orientations could be regarded only as average, because in living samples cell orientation continuously alters. Nevertheless, these average pictures are completely real and highly important for understanding morphogenetic mechanisms.

2.2.2.3.1. Orientation of Ectodermal Myoepithelial Cells in Straightly Growing and Bending Outgrowths.

Cells of the contralateral walls of straightly growing rudiments are oriented always symmetrically. In all cases except some stages of hydranth development, which will be described later, the cells are oriented either normally (perpendicular) to the surface of the rudiment, or their external ends are situated more distally (but never more proximally) than the internal ones. Within these limits the angles between cell axes and rudiment surface can vary considerably.

In the rudiments, which are to be bent soon, cell orientation becomes asymmetrical. In such rudiments the bisector of the angle formed by the axes of cells of the contralateral walls considerably deviates from the rudiment axis in the direction of
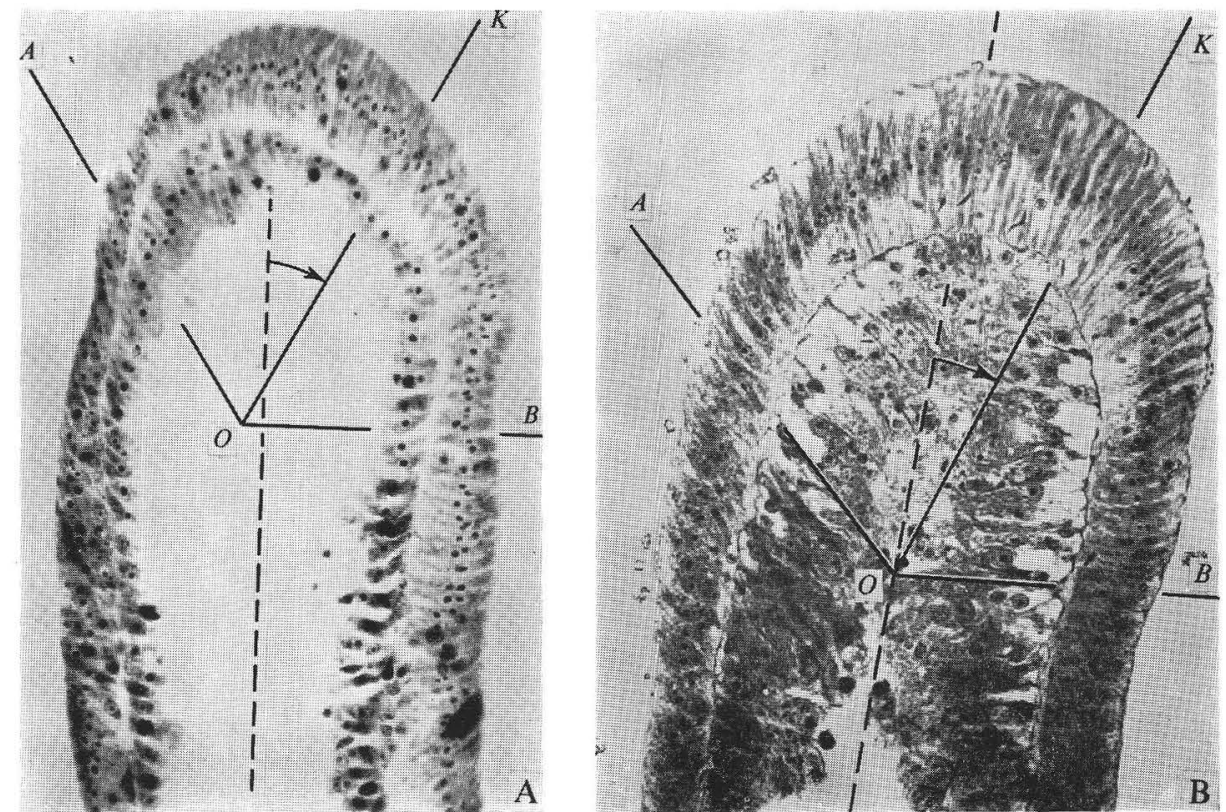

Fig. 12. Cell orientation in stems of Obelia geniculata (A) and $O$. loveni (B) just prior to their bending. $\mathrm{AO}$ and $\mathrm{BO}$ indicate the cell orientation in the opposite stem walls. OK-bisector of angle AOB. Dotted lines indicate median axes of stems. (From Belousov et al., 1972). 
the presumptive bending (Fig. 12, A,B). The corresponding angle varied from $6^{\circ}$ to $25^{\circ}\left(17^{\circ}\right.$ on an average of 6 measurements) for Obelia loveni and from $9^{\circ}$ to $30^{\circ}$ for $O$. geniculata $\left(20^{\circ}\right.$ on an average of 5 measurements). No cases of negative or zerodeviation occurred.

Therefore a bisector of cell axes of the contralateral walls is oriented in such a manner, as if it pointed to the direction of the future bending of rudiment. Such kind of cell orientation may be designed as "prognostical". Some other examples of prognostical orientation will be presented below.

2.2.2.3.2. Alterations of Cell Orientation in Developing Hydranths of $O$. loveni and $D$. pumila.

During the development of $O$. loveni hydranth and D. pumila $\mathrm{CR}$ cell orientation considerably and regularly alters. The initial cell orientation is oblique, the external cell poles being situated more distally than the internal ones. Later on cells begin to turn, tending to orient transversely (Fig. 13). This reorientation is especially pronounced in the distolateral parts of the rudiments, which are mostly expanded. In the advanced stages the most complicated cell reorientations take place in the ectoderm (Fig. 14). In the intermediate stages the cells become U-shaped (Fig. 14,B) and in

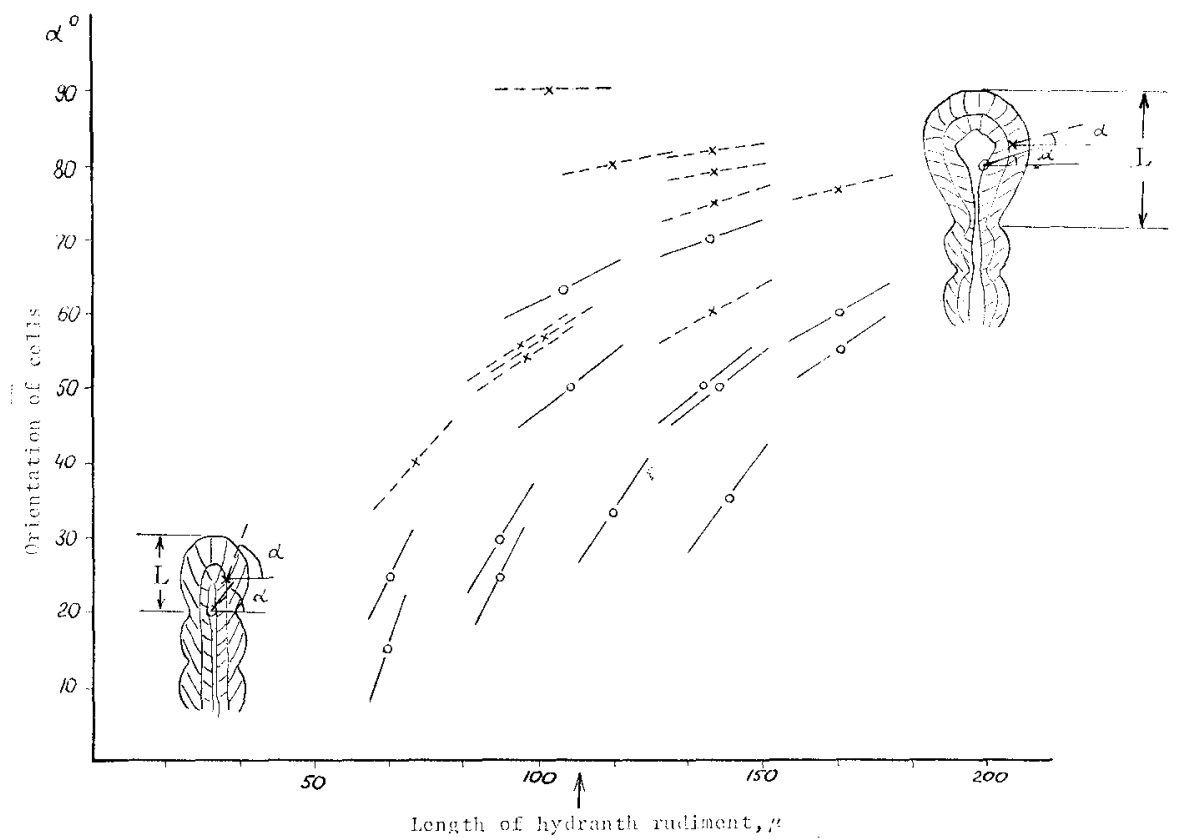

Fig. 13. A diagram of cell reorientation at the early stages of development of $O$. loveni hydranth (left below - initial stage, upper right - final stage of a given period). Absciss-length of hydranth rudiment $(\mu)$ (the arrow indicates the beginning of transverse extension of a rudiment); ordinateorientation of cells. $-\mathrm{x}-$ ectodermal cells, $-\mathrm{O}-$ entodermal cells. (From BeLousov et al., 1972). 
some cases S-shaped (Fig. 14,C). Later they become oriented with their lateral ends proximally (Fig. 14,E). Therefore, the whole angle of their rotation is about $90^{\circ}$ (compare Fig. $14 \mathrm{~A}$ and $\mathrm{E}$ ). The part of the rudiment, composed of such reversed cells is later contracting and transforming to its neck. Meanwhile cell orientation in more proximal regions (near the rudiments base) remains unchanged. As a result, a narrow zone of counter-oriented cells is established near the hydranth (resp. CR) base (Fig. 14,E, dp). Later it transforms to a diaphragm.

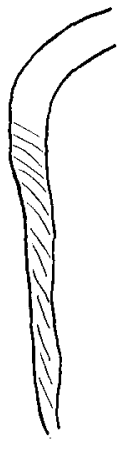

A

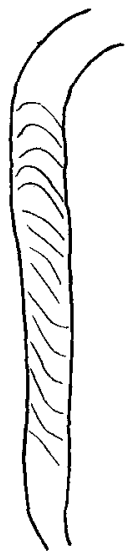

B

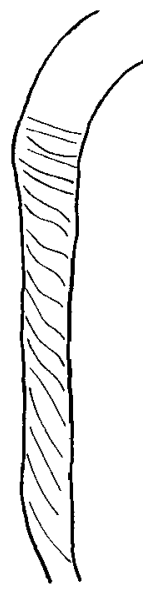

$\mathrm{C}$

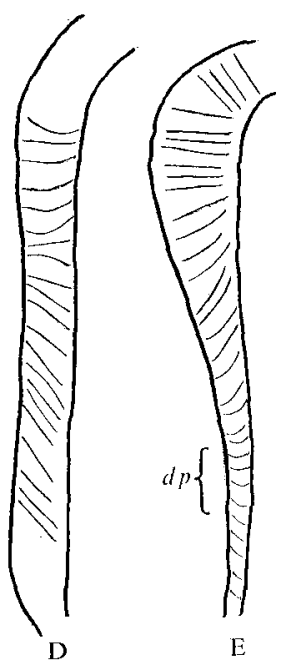

Fig. 14. A-E. Reorientations of ectodermal cells in left side wall of $O$. loveni hydranth at successive stages of its development. dp-rudiment of diaphragm. (From Belousov et al., 1972).

One can see from Fig. 14 that during the cell orientation the wall of hydranth rudiments does not considerably alter its shape. At the same time, cell reorientations are closely corresponding to the presumptive deformations of the sheet in the manner, similar to that of bending rudiments. Namely, if axes of the obliquely oriented cells of early rudiments are prolonged and a curve perpendicular to all of them is plotted, then this curve will obviously be similar to the presumptive flattened contour of hydranth (resp. D. pumila CR) roof (Fig. 15,A). Making the same construction for hydranth rudiment at the stage of "overturned" cells, the contour of differentiated CR with the proximal constricted and distal expanded parts may be "predicted" (Fig. 15,B).

Therefore, cell orientation in developing hydranths and CRs may be also designed as "prognostical". Later on the attempt will be made to reveal the basis of these for the case of purely formal correlations.

2.2.2.4. Cell Reorientations, Alterations of Growth Directions and Shape of $D$. 
pumila Rudiments as a Result of Interactions between LRs and CR.

Cell orientation in LRs is asymmetrical, as in all bending rudiments. Namely, the cells of external walls are oriented more transversely (normally) than those of the internal walls (adjacent to CR). Cells of the both walls of CR are oriented symmetrically (Fig. $15 \mathrm{~A}, 16 \mathrm{~A}$ ). Our experiments in D. pumila pretended to solve the following problems: 1, Are there any causal relations between cell orientation and the direction of a rudiment growth? 2. Is there any influence of a rudiment to cell orientation in another, adjacent rudiment?

The experiments consisted of extirpation of a CR and one of LRs (see for details BeLousov, 1965) and in breaking the continuity of CR layers by simple cutting or by insertion of a thin $(15 \mu)$ celloidine membrane (to prevent regeneration, which was very rapid after cutting).

The results were as follows.

1. After the removal of CR pronounced "normalization" of cell orientation took place in the internal walls of the both LRs. Thus, cell orientation in the opposite walls of the LRs became almost symmetrical. In these experiments LRs were growing straightly upwards without bending lateralwards (38 cases out of 43)-compare Fig. 16 B,C, with Fig. 16,A.

2. After the removal of a LR "normalization" of cell orientation in relation to b.m. took place in the adjacent wall of the CR (Fig. 16,D). As a result, cell orientation in CR became asymmetrical, "predicting", according to the above laws (2.2.2.3.1), the CR bent towards the removed LR. This result has just been observed in 31 cases out of 33 (Fig. 16E).

3. If the structural connections between $\mathrm{C}$ and LR are broken by means of membrane insertion, LR grows more vertically than normal, whereas cell orientation in the adjacent wall of $C R$ has been sufficiently normalized (10 cases, Fig. 16F). The result was as if each of the separated rudiments ceased to "feel the presence" of its neighbour (as if the latter were completely removed). One might stress that the first signs of cell normalization in the ectoderm of the adjacent CR wall became visible already in several minutes after removal or even dissection of a LR (Fig. 16,G); see also $(2.2 .3 .1$.)

These results permit to give positive answers to the both of above questions. Obviously each rudiment exerts certain influence to the neighbouring one, forcing the cells of the adjacent wall of the latter to orient more obliquely, and alters thus the direction of its growth. The correlation of alterations in growth directions with those in cell orientation argues in favour of real causal relations between the both processes.

At the same time, these experiments demonstrate the existence of a certain intrinsic tendency of cells of a given layer to orient normally in the absence of any external influences (normalization of cells of CR wall after the removal or, at least, after breaking of mechanical contacts with the adjacent LR). 

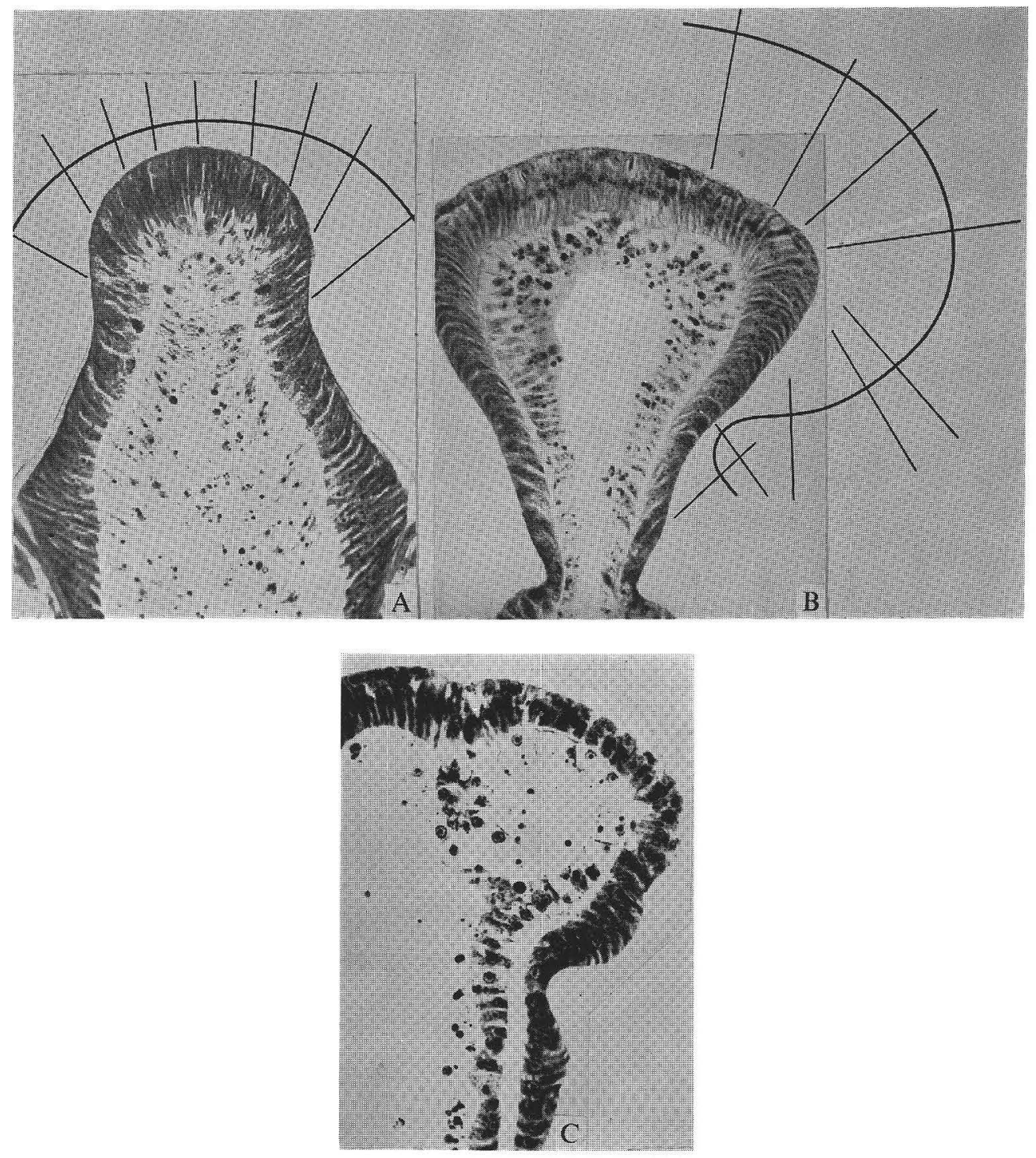

Fig. 15. A-C. Three successive stages of development of CR in Dynamena pumila. The line perpendicular to the distal segments of the ectodermal cell axes is approximately similar to the contour of the succeeding stage. (From Belousov et al., 1972). 

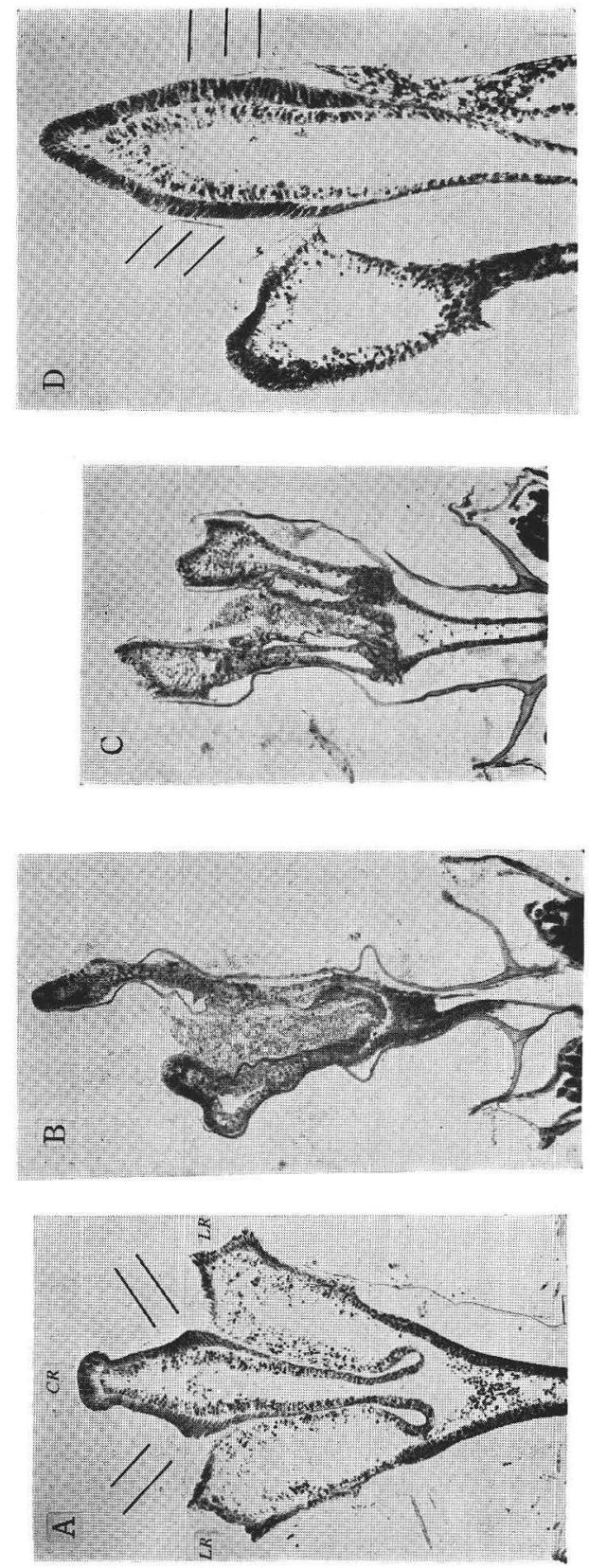
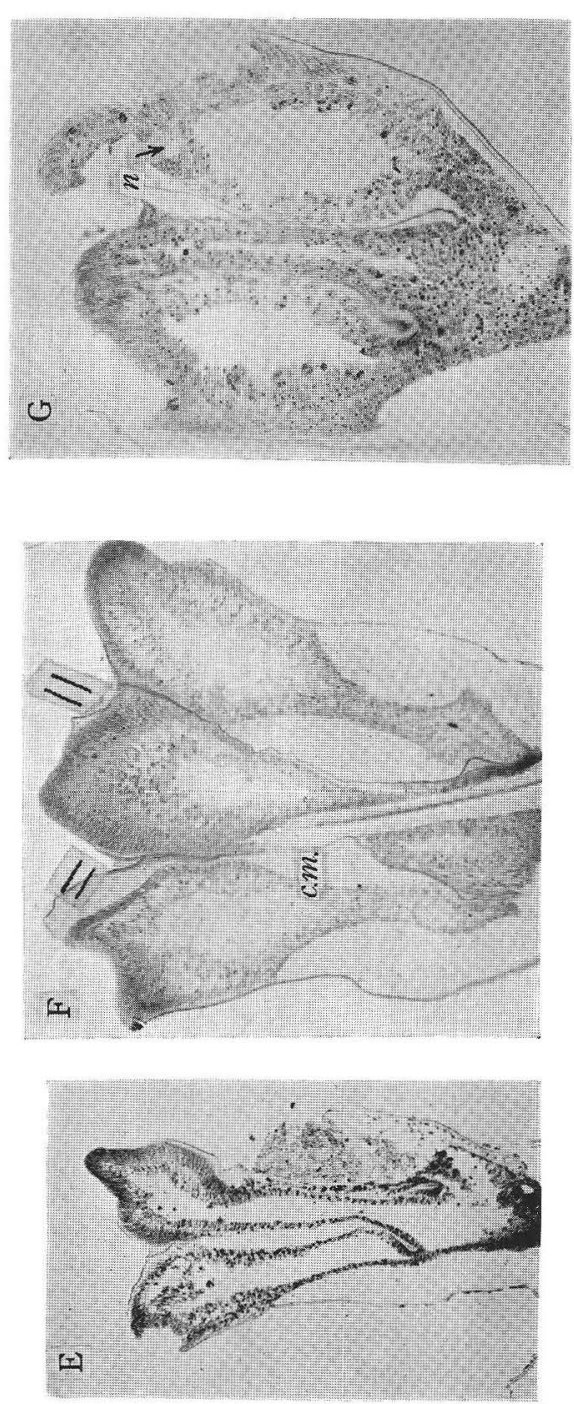
The described results will be interpreted later (3.3.).

2.2.3. Mechanical Stresses in Developing Rudiments of Hydroid Polyps.

Some data and correlations described above, namely the very structure of hydroid ectoderm, consisting of active myoepithelial cells and two evidently passive enveloping membranes (plasmalemma and b.m.), and the phenomenon of "prognostic" cell orientation lead to the idea that in a developing rudiment there can be an unstable equilibrium between the "conservative" and the morphogenetic forces. If this is the case, one can expect very rapid shape alterations, similar to the normal ones after complete or partial separation of the active parts of a rudiment from the mechanically inert ones. On the other hand, if the active morphogenetic forces are decreased anyway, not only the retardation or ceasing, but also even a certain reversion of a developmental course may be expected, due to the action of "conservative forces". The experiments to demonstrate these two are described below.

2.2.3.1. Rapid Shape Alterations in Separated Parts of Developing Rudiments of $O$. loveni and D. pumila.

The easiest way to diminish the "conservative forces" of mechanical resistance and to make thus the expected mechanical stresses visible is to dissect the developing rudiments and to trace their behaviours. The corresponding operations and their results are presented in Figs. 17 and 18. Along with separation of the distal parts of rudiments from the proximal ones, in some cases the ectodermal layer was separated from the entodermal one and (or) the parabasal part of ectoderm (adjacent to basal membrane and including myofibrillar net) was separated from its external part.

If a roof of as yet completely smooth CR of D. pumila is dissected unilaterally, there will occur in 1-3 min a pronounced folding, resembling that of normal differentiated CR, though not so regular (Fig. 17,A). If a lateral wall of $\mathrm{CR}$ is dissected approximately at the same stage near its base, the roof inclines, the dissected wall contracts and slightly bends inwards, also imitating the normal processes of formation of hydranth neck (Fig. 17,B).

If $\mathrm{CR}$ is split on a vertical plane, its parts immediately removed from each other will become closed in $15-30 \mathrm{~min}$. In closing process the most active role is played by entodermal cells. The width of a slit and the shape of the closed parts considerably depend on the orientation of the cutting plane. If the latter coincides with the sagittal plane, the slit becomes wider than in the case of frontal orientation and the dissected

Fig. 16. Results of the experiments on D. pumila rudiments. A-control growing tip with symmetrically bent LRs. B, C-vertical growth of LRs after removal of CR. D-asymmetrical cell orientation in contralateral walls of as yet symmetrical CR after removal of right LR. Einclination of CR towards the removed right LR. F- "verticalization" of left LR and normalization of cell orientation in the left wall of CR after the insertion of a celloidine membrane (c.m.). $\mathrm{G}$ - the beginning of cell normalization ( $\mathrm{n}$ ) in right wall of CR after the dissection of the right LR (indicated by arrow). Note also the lateralwards turning of the dissected LRs roof. In A, D, F directions of cell axes are indicates (A, D from Belousov et al., 1972; B, C from Belousov, 1965). 


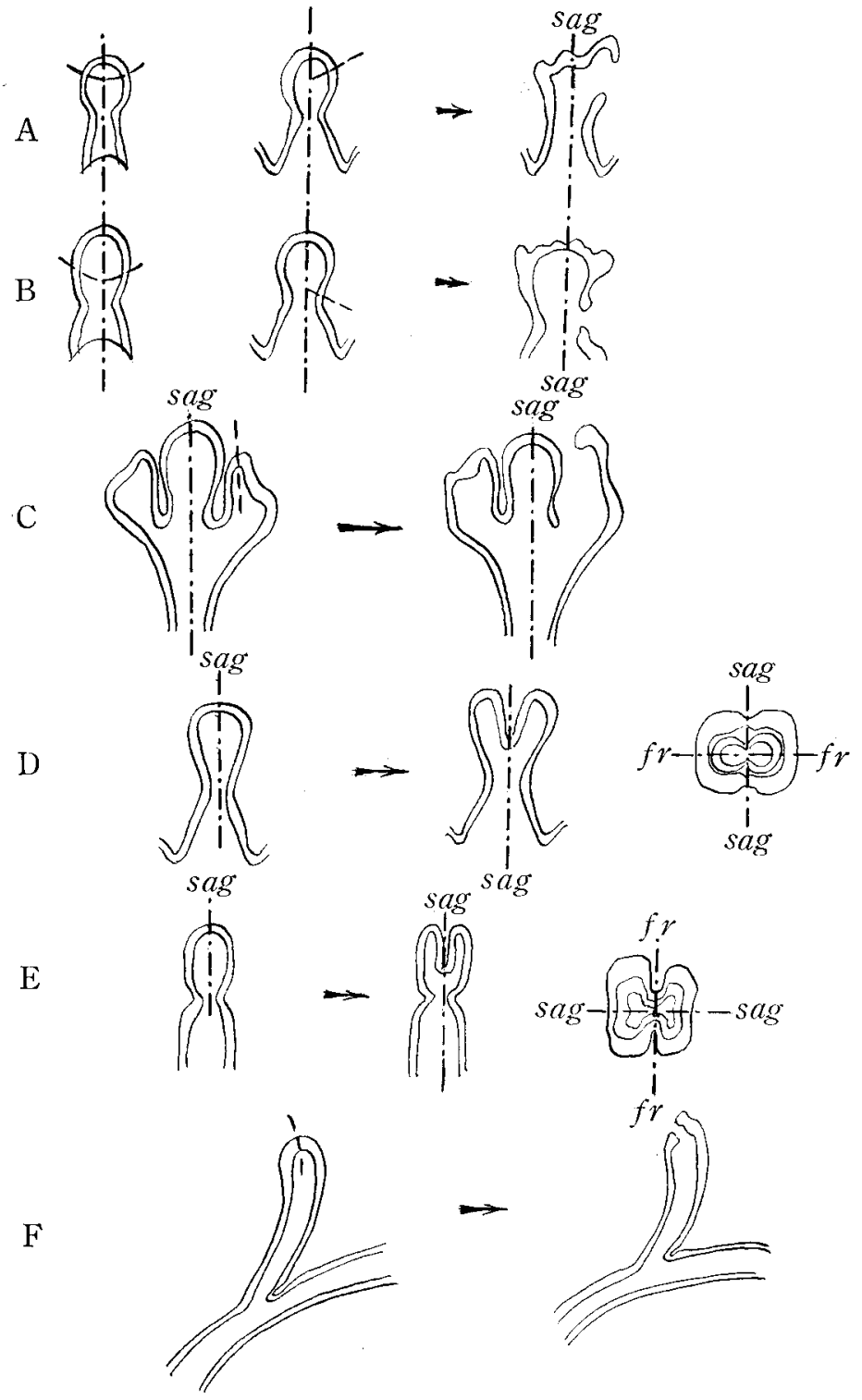

Fig. 17. Schematical representations of rapid shape alterations after dissection in $D$. pumila (A-E) and O. loveni (F). Dotted lines - directions of cutting. Orientations of sagittal (sag) and frontal $\left(\mathrm{f}_{2}\right)$ planes are indicated in A-E. Other explanations in text. 

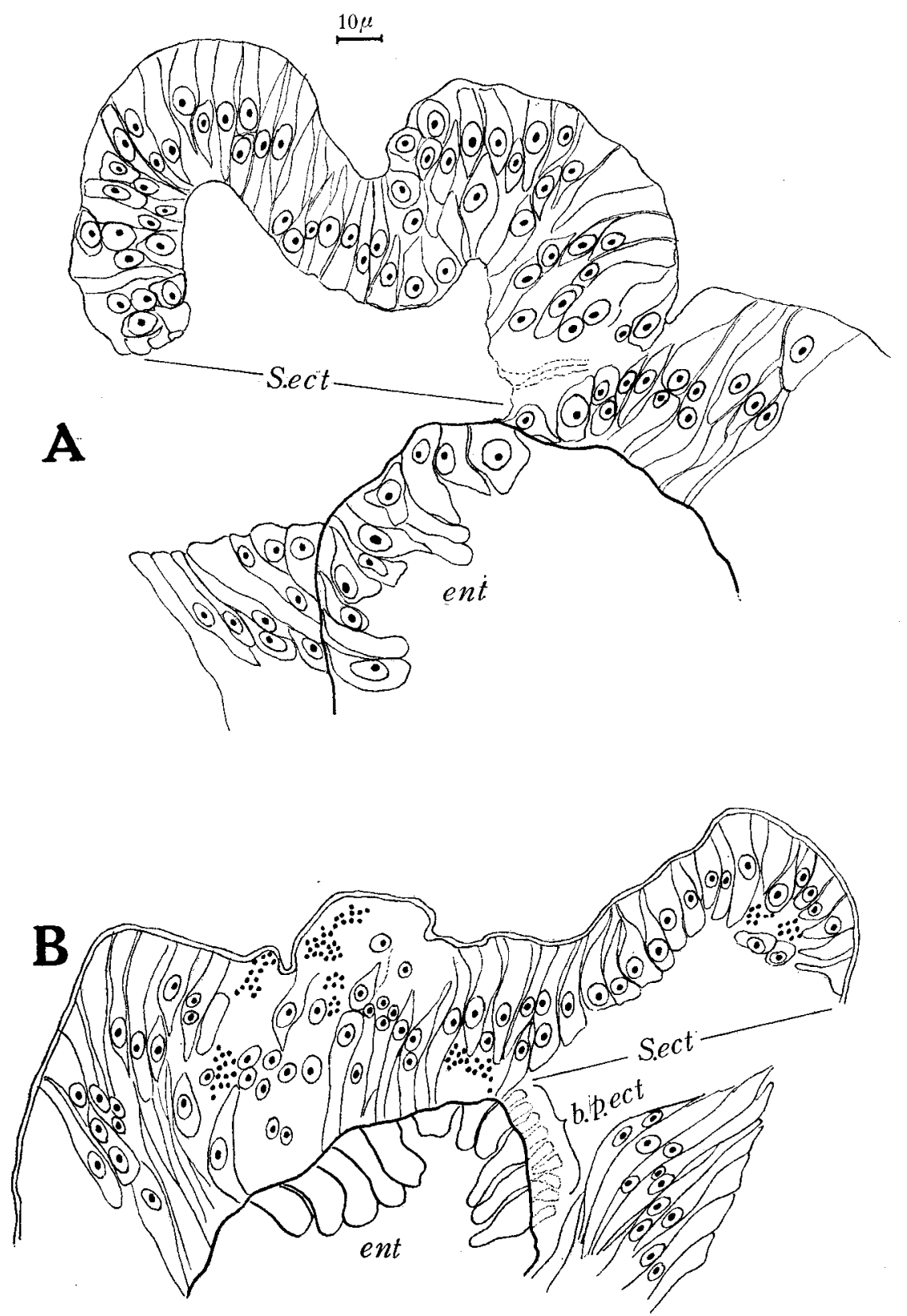

Fig. 18. Two examples of the rapid folding of the roof ectoderm of $D$. pumila CR after its separation from the entoderm (A) and, in addition, from the basal parts of the ectodermal cells itself (B). S. ect.- -separated part of ectoderm (note a considerable contraction of its cells as compared with those of intact area), ent--entoderm, b.p. ect.-basal parts of ectodermal cells, containing myofibrills. 
parts become circular on a transverse plane (Fig. 17D). In the case of frontal orientation of the cutting surface the dissected parts take elongated shape (Fig. 17E).

All the observed phenomena also may be interpreted as indications of mechanical stresses, distributed in the same way as in the normal morphogenesis: the wide split after sagittal cutting corresponds to the normal tendency of CR to expand on frontal, but not on sagittal plane; the distribution of curvature in transverse sections is also similar to that of the normal rudiments (the maximal curvature of CR is invariably localized at the frontal poles).

If the tip of growing $O$. loveni stem is split, the similar phenomena of immediate widening of the slit and of shifting of dissected parts take place (Fig. 17,F), demonstrating the existence of the oppositely directed mechanical tensions in the contralateral walls of a stem.

These facts demonstrate that the studied rudiments are mechanically stressed, so that the decreasing or elimination of mechanical resistance of the neighbouring (as a rule, more proximal) parts leads to the immediate or at least very rapid deformations. It is natural to attribute these stresses to the action of one or both of the contractile systems, i.e. tono- or/and myofibrillar systems. The following histological data permit to specify the situation.

A part of ectoderm, separated from entoderm and from the basal part of the ectoderm itself (and thus devoid of myofibrills) is not only capable of a rapid folding but folds even more rapidly and intensively than intact ectoderm layer (Fig. 18,A,B). The impression arises that myofibrillar system (if it really presents in these regions of hydroid body, see 2.2.1.) not only does not promote, but, on the contrary, prevents ectodermal folding. At the same time, ectodermal cells of the separated zone are contracted 1.5 times on an average as compared with the analogous cells of intact zones. This can be due only to tonofibrillar contraction. The majority of contracted cells become triangular, the bases of triangles forming the convex surfaces of the folds. Therefore, myoepithelial cells are capable of rapid transformation from an initial extended spindle shape to a contracted tiangular shape by the action of tonofibrillar system.

One may conclude that the above experiments demonstrate the existence of mechanical stresses in hydroid tissues, which are evidently a result of the action of tonofibrillar system, and leading to geometrical reconstructions, similar to those in normal morphogenesis. It is worth notice that the experiments give no direct answer, whether the stresses are really preexisted; the possibility remains that they arise do novo, as a reflectory response to the operation. However, this point is not of primary importance for us, because in any case the capacity of hydroid tissues of a rapid development of morphogenesis-imitating stresses remains doubtless, whatever is their immediate cause. It will be demonstrated later that in normal hydrozoan development the stressed and relaxed states are regularly alternated.

2.2.3.2. Reversibility of Morphogenesis as a Result of Action of Metabolic In- 
hibitors.

Pieces of Obelia colonies including hydranth rudiments were immersed in 0.05 M KCN or $1-2 \%$ dinitrophenol at different moments after the beginning of contraction of its proximal part (i.e. neck formation, Fig. 5,F). In samples immersed not later than 1 hour after the beginning of neck formation, the neck completely disappeared in half an hour; in other words, the proximal parts of the rudiments expanded again (23 cases out of 26). Vital staining and histological examination did not reveal any signs of cell degeneration at the time of expansion. In samples immersed in inhibitor solutions later than an hour after neck formation, the neck failed to expand even if complete cell degeneration took place. Thus, one may assume the existence of a certain critical point in hydranth morphogenesis, after which the contraction of the proximal part is stabilized.

These experiments directly demonstrate that just arisen rudiment shape is unstable and requires a continuous energy supply not only for its further evolution, but solely for its maintenance. It is natural to suppose that the energy is used by actively contracted myoepithelial cells in order to overcome the mechanical resistance of passive membranes (plasmalemma and b.m.). In depressed samples, on the contrary, the elastic forces of the membranes overcome the morphogenetic forces of contracting cells, thus reversing the course of morphogenesis. This demonstrates clearly the elastic properties of membranes. At the same time, however, shape stabilization, achieved in some hours after establishing of a given configuration, points out that the membranes have lost their elastic properties. In mechanics many examples of the bodies are known to change their elastic properties to the plastic ones under the conditions of the continuous pressure (so-called elasto-plastic bodies). It seems probable and even expedient for the actively growing organisms to possess the supporting structures with such properties. Indeed, they prevent small and casual cell shifts (which are taking place from time to time in the proximal regions of hydrozoan colonies) and stabilize the results of massive and vast shifts which play a leading role in growth and shaping.

2.2.4. Growth and Morphogenesis in $O$. loveni and D. pumila according to TimeLapse Studies.

The main result of time-lapse studies was the detailed investigation of so-called "growth pulsations" in Hydrozoa.

2.2.4.1. General Description and Macropicture of Growth Pulsations.

Growth pulsations in hydroids have been recently discovered by several authors. ${ }^{5)}$ Hale (1960) described very similar, though not at all identical, phenomena of periodical contractions-extensions of coenosarc in Clytia johnstoni. BeLoussov (1961) registered the periodical "growth pushes" in $O$. loveni, using long-exposure photography (the method did not permit to reveal the reversal phases of pulsations). A thorough description of growth pulsations in Campanularia stolons was made by

5) As I have just found, the first obviously was SaINT-HiLAIRE (1930). 
WytTENBACH (1968). He stressed the independence of pulsations of growing tip from the periodical contractions of more proximal parts of coenosarc and, thus, the autonomous pulsatory activity of a tip region.

However, micromechanisms, underlying pulsatory activity, have remained up to now unknown.

Generally, three kinds of growth pulsations may be distinguished:

1. Longitudinal pulsations of growing tip, i.e. periodical extensions-retractions of a growing rudiment (each retraction is, obviously, smaller than each periodical extension). This is the most pronounced kind of pulsatory processes in Hydrozoa.

2. "Shaping" pulsations. Not only the longitudinal dimensions, but, so to say, the whole shape of hydrozoan rudiments alters periodically. "Shaping" pulsations will be demonstrated to be closely correlated with the "longitudinal" ones.

3. Periodical transversal expansions-contractions of the subapical part of coenosarc. These easily observable periodical processes seem, according to WYTTENBACH's (1968) and our own opinion (see below), to have no direct relations with the first two kinds of pulsations.

Longitudinal pulsations of growing tips of D. pumila $\mathrm{CR}$ and $O$. loveni stem, plotted from time-lapse films, are presented in Figs. 19 and 20. One can see that in D. pumila short (2-4 min) periods of rudiment contractions are alternated with its more prolonged (10-13 min) extension. Thus, the duration of the whole cycle is about 12-15 min, its amplitude about $15-20 \mu$. The average rate of growth is fairly constant during the whole period of observations. Similar growth pulsations were observed on LRs. As a rule, they took place in counterphase in respect to CR pulsation (for details see 2.2.4.2.3.).

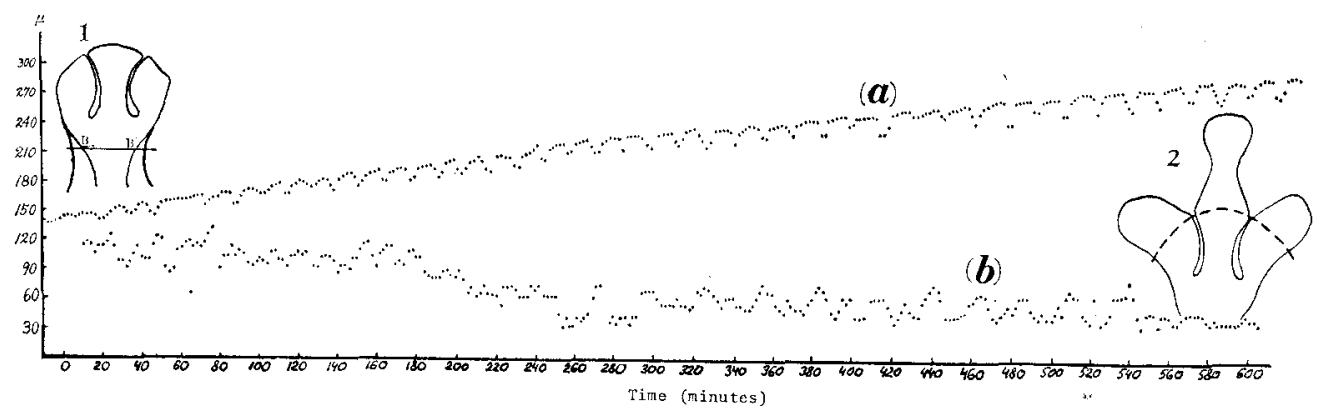

Fig. 19. Pulsations of the growing tip (a) and coenosarc (b) in Dynamena pumila. 1-initial, 2-final stage of a studied period. BB indicates the level at which the coenosare diameter was measured. The dotted arch at 2 indicates the position of the distal surface of the rudiment at the initial stage 1. (From Belousov et al., 1972).

In $O$. loveni the amplitude of tip pulsations was smaller and less constant. However, using water-immersion $\times 40,5-8$ min period pulsations were constantly observed in Obelia stems and hydranths. The period of pulsation was much more stable than 


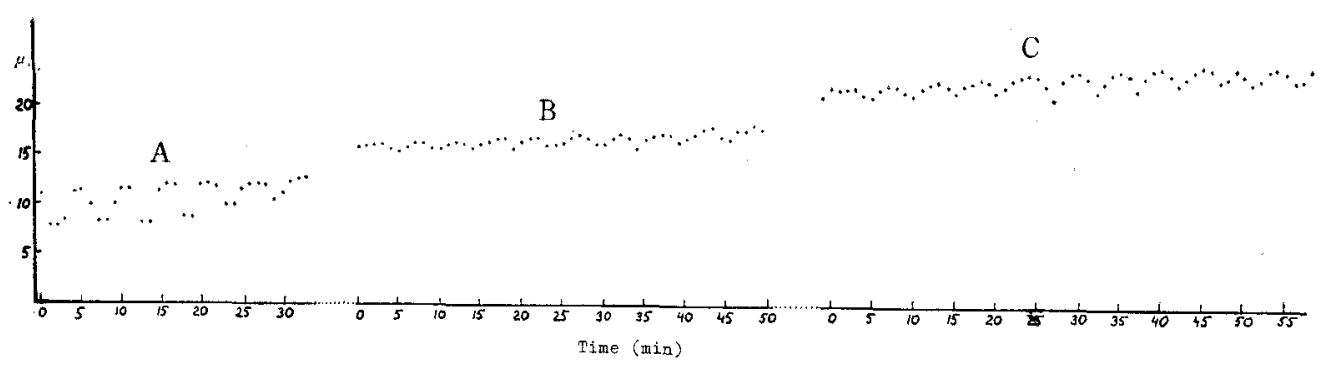

Fig. 20. Pulsations of the tip in growing Obelia loveni stem. A, B, C-successive periods of stem growth, at intervals of 1 hour. (From BeLousov et al., 1972).

its amplitude (Fig. 20).

Correlations of distalwards shift rates of ecto- and entodermal tip cells during longitudinal pulsations in $O$. loveni. Already by means of visual observations a considerable and regular variation in the thickness (height) of the tip ectoderm could be registered. Generally, three different kinds of rate correlations were observed:

1. The rates of movement of tip cells in both layers were approximately equal (Fig. 21,A). This situation was typical mainly for the smooth growth period when no grooves appeared (a period between the formation of $n_{1}$ and $n_{2}$, Fig. 5, D).

2. The rate of movement of ectodermal tip cells exceeded that of the entodermal cells. As a result, the thickness of ectodermal layer could be approximately doubled (Fig. 21,B). This situation was typical mainly for the first period of groove formation (just after the initiation of a stem) (Fig. 5,B, $\mathbf{n}_{1}$ ).

3. The rate of migration of ectodermal cells was less than that of entodermal cells (Fig. 21,C). As a result, the attenuation of ectodermal layer and the more compact arrangement of the tip cells of the two layers took place. The situation was typical for the early stages of hydranth development.

The described kinds of rate correlations are much more various than that described by Wyttenbach (1968) for Campanularia stolons. WytTenBach observed only a periodical "pushing" of ectodermal cells by entodermal ones, which led him to conclude the passivity of ectoderm. Meanwhile, in vertical Obelia stems quite the opposite (type 2) is observed along with the analogous rate correlations (type 3). The latter is incompatible with the assumption of passive ectodermal shift. As a whole, the existence of the different types of rate correlations demonstrate the lack of strict connections between the both layers and thus their independent shifting activity (see also 2.2.4.2.1.).

Shaping pulsations. Already during the above described longitudinal pulsations the shape of a tip does not remain constant. Periodical alterations of its configuration were mostly pronounced in CR of $D$. pumila: during the maximal extension CRs roof became convex, whereas during the maximal retraction it became sharply concave. In 

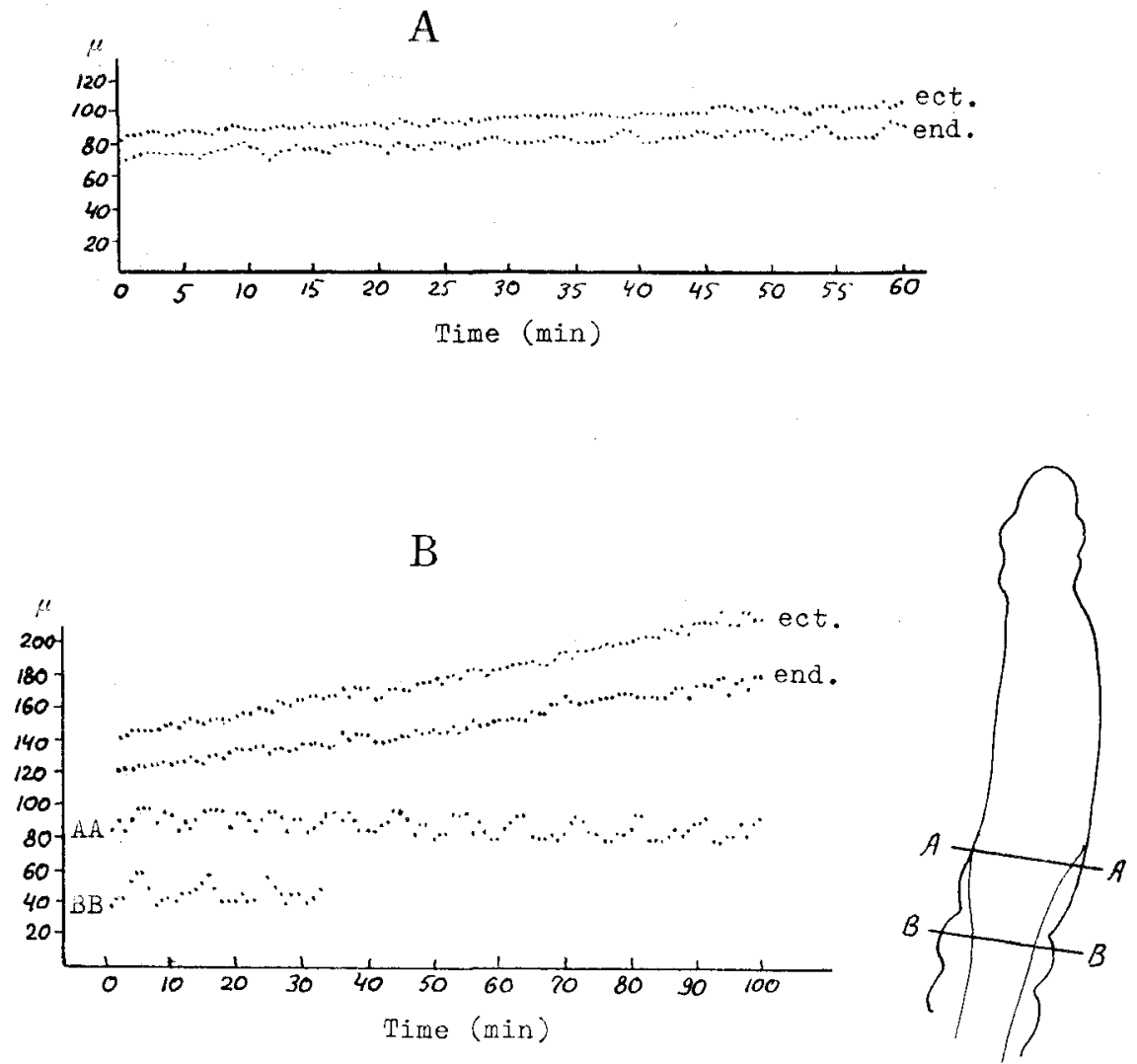

C

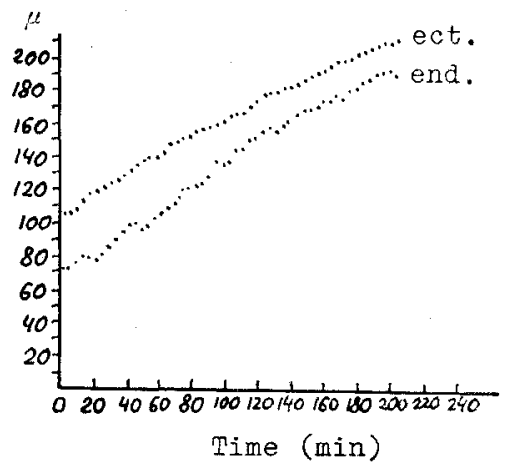

Fig. 21. A-C. Different kinds of rate correlations of ecto- and ento-dermal tip cells in Obelia loveni. AA, BB-contractions of coenosarc diameters at these levels are indicated on the left. (From Belousov et al., 1972). 
$O$. loveni outgrowths, during the maximal retraction the roof only slightly flattened.

Much more complex shaping pulsations can be observed in developing $O$. loven hydranths and $D$. pumila $C R s$ at higher magnifications and shorter exposure intervals. Namely, each protuberance and depression periodically becomes more or less pronounced (Fig. 22, A-D) and, thus, the whole contour becomes more or less in relief. This is due to the fact that each protuberance is growing by periodical outwards "pushes", approximately coinciding with the extension phase of the whole rudiment (for more exact description see below). During the retraction phase each protuberance also retracts to some extent, but less than the surrounding more flat areas. As a result, during the retraction phase a rudiment also possesses a sharp relief, though of a different character from that in the extension phase.

Periodical transversal expansions-contractions of coenosarc are presented at Fig. 19 (b-b line) and Fig. 21 B (AA, BB). As one can see, no obvious correspondence is
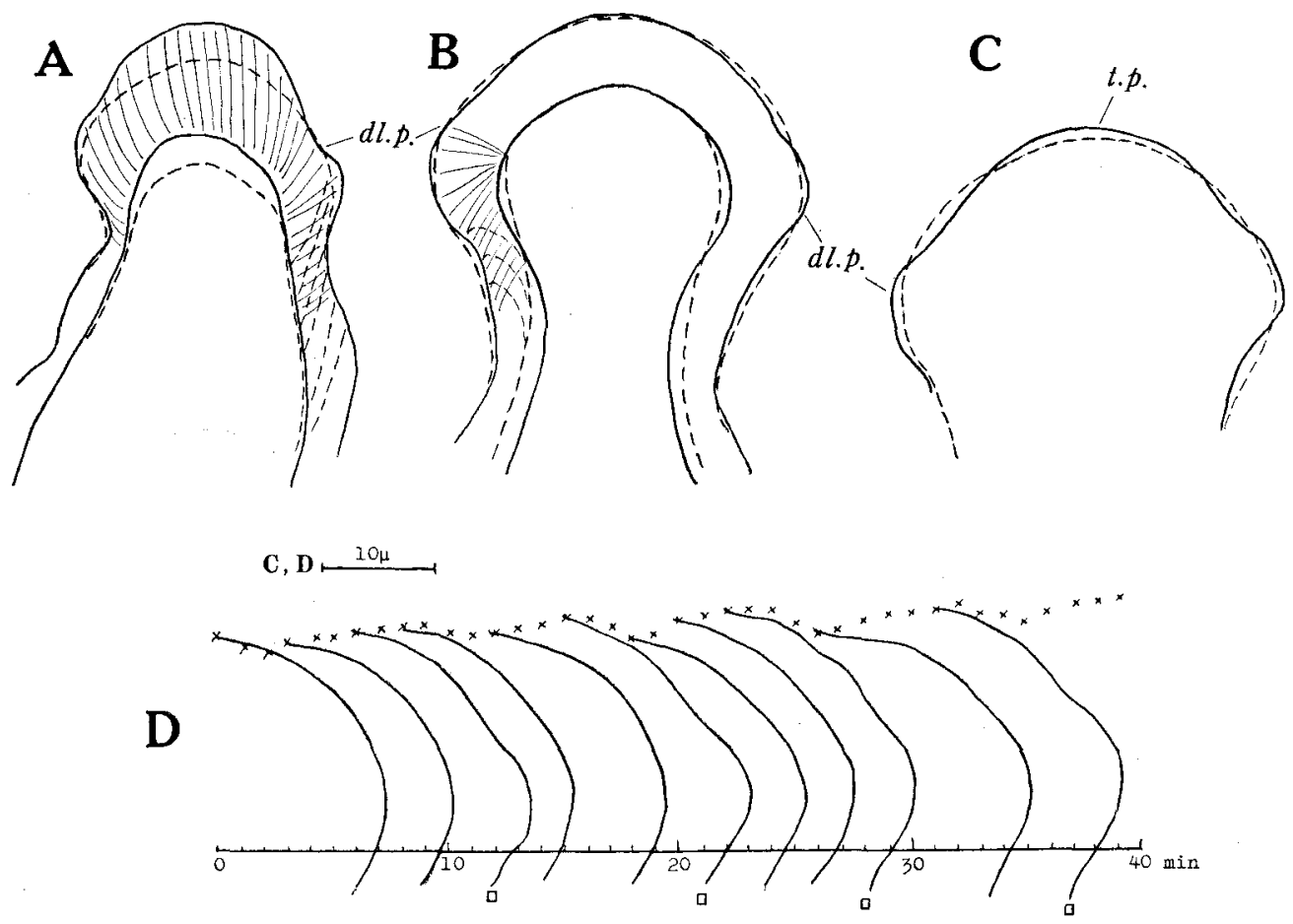

Fig. 22. Several examples of shape pulsations (drawings from time-lapse films). A-superposition of configurations of the opposite phases of a growth pulsation in $O$. loveni stem. B-the same for $D$. pumila $\mathrm{CR}, \mathrm{C}$-for $O$. loveni hydranth. D-successive phases of pulsation of hydranth rudiment in O. loveni. In A, B, C solid lines correspond to maxima of upward phases, while the dotted lines to maxima of downward phases. In A, B the positions of an external surface, of b.m. and of group of ectodermal cells are indicated, while in C, D only the contours of external surface are presented. dl.p.--distolateral protuberance; t.p.--tip protuberance (C, D, from BELOusov et al., 1972) 
observed between these oscillations and longitudinal pulsations of the same rudiments. That is why the both kinds of pulsatory processes seem to be independent. Another argument is that in our experiments as well as in WYTTENBACH's ones longitudinal pulsations of a small isolated tip region, lacking a zone of transversal contractions, were observed.

2.2.4.2. Micropicture of Growth Pulsations.

Using short $(1-5 \mathrm{sec})$ exposure intervals it became possible to trace the behaviour of individual cells in growing zones. Combining these data with histological ones, a detailed picture of cell behavior could be reconstructed.

Cell behaviour, underlying growth pulsations, is generally the same in $O$. loveni and D. pumila. The only specific feature of $D$. pumila, which is to be mentioned, is a particular "counterphase" activity in adjacent walls of C and LRs (2.2.4.2.3.).

2.2.4.2.1. Micropicture of Longitudinal Pulsations.

Firstly, the description of the behaviour of ectodermal cells will be started with the end of "downwards" (reversion) phase. At the moment the ectodermal cells are oriented obliquely, with their external ends upwards (Fig. 23 A, 24 A). The most pronounced sign of the upwards phase is the upwards shift of the large area of b.m. In growing stems of $O$. loveni the shifting area spreads far proximally, whereas in hydranths it is limited from the proximal side by diaphragm; in $D$. pumila CRs the proximal border of the shifting area approximately coincides with the level of LRs.

During the first part of the upwards phase $(1 / 3$ of its total duration in Obelia stems, continuing for $1 \mathrm{~min}$ ) the b.m. shifts upwards as a single solid body: the rudi-

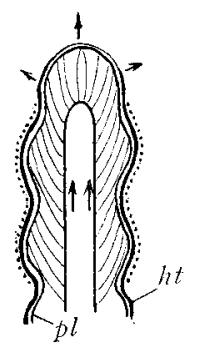

A

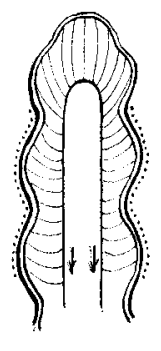

B

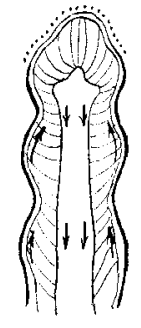

C

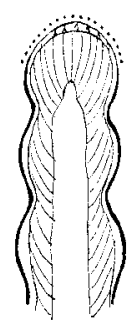

$\mathrm{D}$

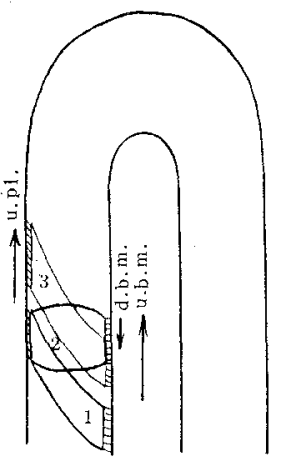

E

Fig. 23. A scheme of cell shifts and reorientations during the growth pulsation in $O$. loveni stem. A-D - successive phases of growth cycle. ht - hydrotheca; pl-plasmalemma. The arrows indicate directions of shifts, subsequent to a given phase. Dotted areas indicate localization of supporting structures at a given phase. Note close contacts between ht and $\mathrm{pl}$ at $\mathrm{A}, \mathrm{B}$ and their gradual detachment at C, D (except of the apical area). E-a scheme of cell shifts during the growth cycle. 1-3--successive positions of a cell, u.b.m.--upwards shift of basal membrane, d.b.w.- downwards shift of b.m., u.pl.-upwards shift of plasmalemma. 
ment tip shifts upwards with the same rate. The same is true as well for the internal ends of the ectodermal cells which behave as if they were closely attached to the b.m. This leads to the more or less complete "normalization" of cell orientation in respect to b.m. (Fig. 23 B, 24 B). Afterwards the upwards shift of the b.m. and of internal ends of ectodermal cells starts to spread as a proximo-distal wave: firstly the more proximal parts continue to shift, then the distal ones. The impression arises as if the shifting area overcomes a certain external resistance to its further movement, applied from the distal end of a rudiment. During this phase an expansion of a rudiment at some distance below its tip takes place. This phase takes the other $2 / 3$ of the whole duration of the upwards phase, for about $2 \mathrm{~min}$ in Obelia stems. In D. pumila there are no pronounced distinctions between the two parts of the upwards phase.

After a certain pause (around $1 \mathrm{~min}$ in Obelia) a downwards shift of the b.m. begins, accompanied by the similar shift of the internal ends of ectodermal cells. This shift begins in both species from the proximal regions (Fig. 23, C) and spreads distally (upwards) with the rate around $30 \mu / \mathrm{min}$ in Obelia and $50 \mu / \mathrm{min}$ in Dynamena. The total duration of the downwards phase in both species is around $3 \mathrm{~min}$. The tip of the rudiment at that time also moves downwards. At the end of downwards phase of a majority of pulsations (but not in each), a remarkable process of rapid (no more than $0.5 \mathrm{~min}$ ) upwards shift of the external ends of ectodermal cells takes place (Fig. 23,D). Then the next upwards phase begins, and so on. The whole scheme of a growth pulse is presented in Fig. 23,E; see also Fig. 22, A,B.

The behaviour of entodermal cells is generally similar to that of ectodermal ones: the same phases of upwards and downwards shifts of their internal ends take place, approximately in accordance with the similar phases in ectoderm. In Obelia during stem growth the ectodermal shifts are more pronounced than the entodermal ones, whereas at the earlier stages of hydranth formation the reverse situation takes place. This corresponds with the above-mentioned correlations of the growth rates of the both layers (2.2.4.2.).

When analyzing short time-lapse films, a marked inequality of shifting rates of the both layers can be observed during a number of successive upwards shifts. The layers really glide in relation to each other.

In histological pictures (Figs. 25-27) changes in cell orientation and cell length are especially well pronounced. In both species, the angle of cell orientation in respect to b.m. changes from $30-40^{\circ}$ (downwards phase-Fig. 24, A; 25, A; 26, A) to $90^{\circ}$ (upwards phase-Fig. 25,B,C; 26,B; 27,B), whereas the length of ectodermal cells decreases at the same time by $1.5-2$ times. This demonstrates that not only normalization of cell orientation, but also their considerable contraction is taking place during the upwards phase. Another remarkable process, easily reconstructed histologically, is the "repacking" of ectodermal cells during their normalization. Namely, comparing Fig. 27, A with B, one can see that in order to obtain transformation A-B, the cells have to glide over one another, being at the same time strictly bounded by b.m. and plas- 

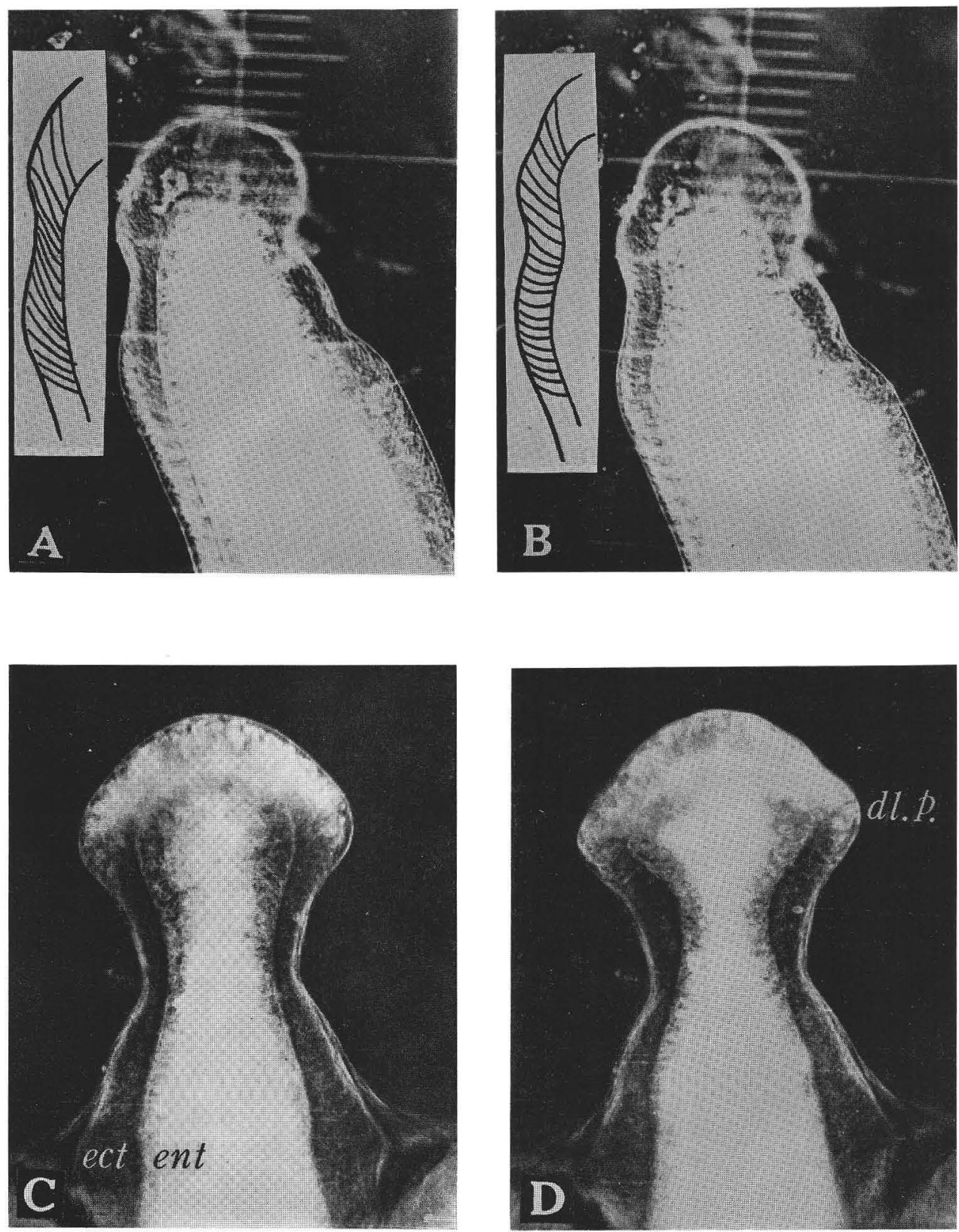

Fig. 24. Frames of different phases of growth and shaping pulsations in $O$. loveni stem $(\mathrm{A}, \mathrm{B})$ and D. pumila CR (C, D). A, C-maximum of downwards shift, B, D-maximum of upwards (resp. lateralwards) shift; ect-ectoderm, ent-entoderm. In A, B cell orientation in the left lateral wall is indicated. Note a marked distolateral protuberance in $D$ (dl.p.) in contrast with the smoothness of CR contours in C. Time lapse between A and B is $200 \mathrm{sec}$, between C and D 270 sec. 

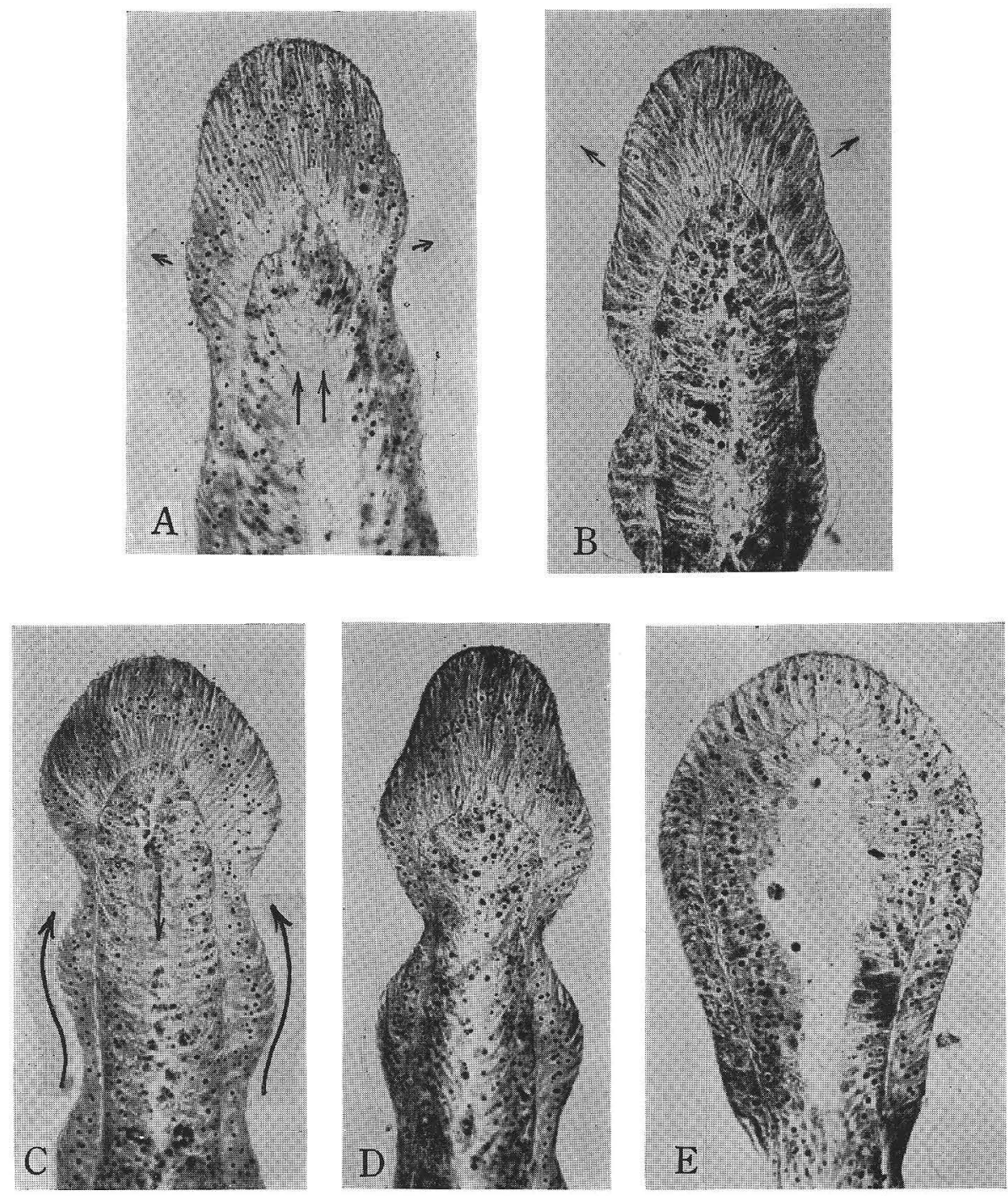

Fig. 25. Histological pictures of different phases of growth pulsations in $O$. loveni rudiments. A-Dsuccessive phases of growth pulsations in a stem (compare with Fig. 22, A-C). The arrows indicate the directions of successive shifts (in C, D the upward shift of external ends of ectodermal cells is taking place). E-rudiment of $O$. loveni hydranth during the contraction of cells of its distal half (in the proximal parts a downwards shift is beginning).

malemma. One may stress as well that during these three simultaneous processes (contraction-gliding-normalization) cell density in ectodermal layer of $D$. pumila $\mathrm{CR}$ is decreased by up to 2 times (a segment of ectodermal layer during the downwards phase contains almost twice as much cells as the same segment during the upwards phase). This is undoubtedly the result of cell "repacking" and of increase in diameter 

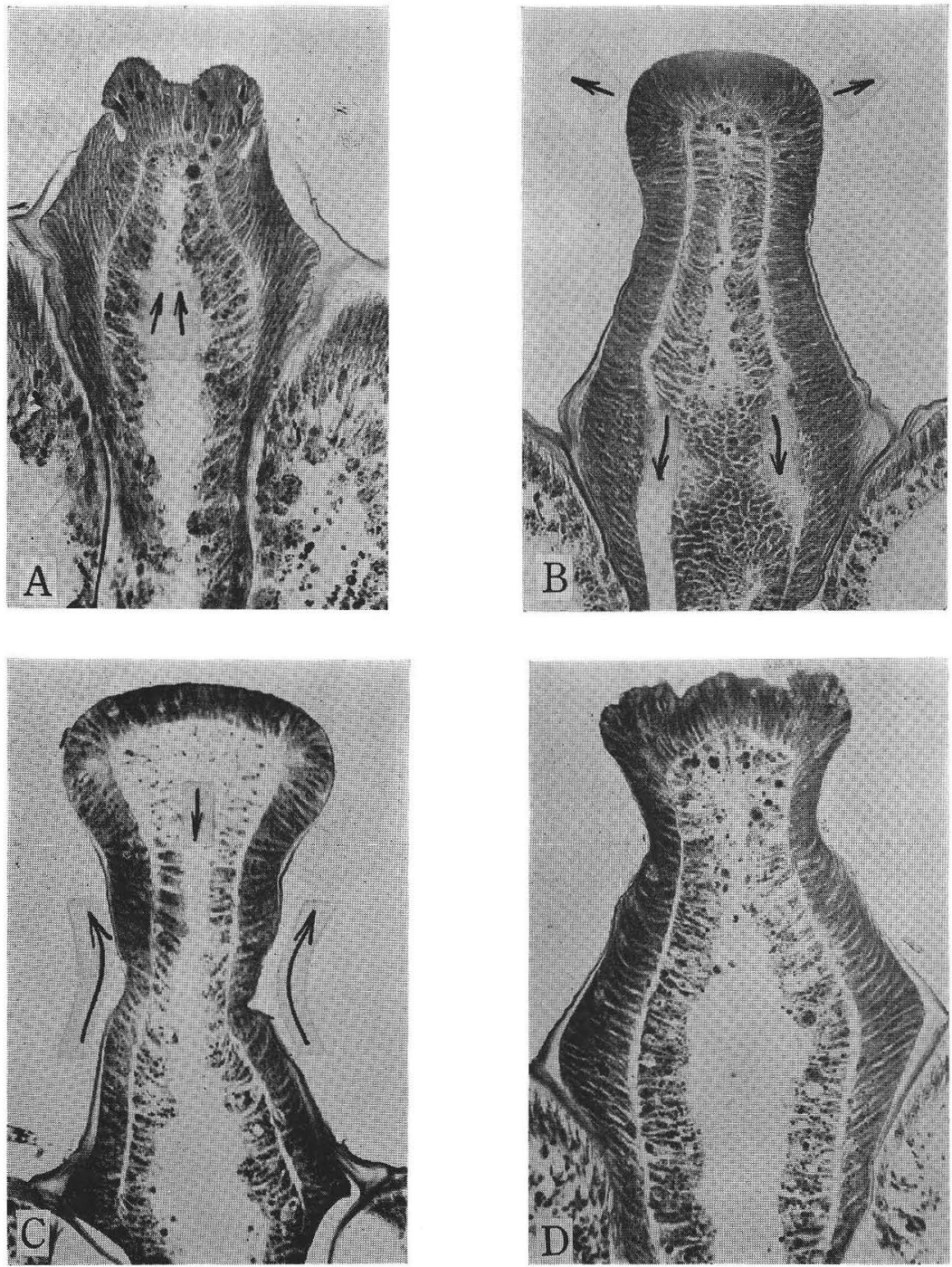

Fig. 26. A-D. Histological pictures of successive phases of growth pulsations in $D$. pumila C. R. A-maximum of downwards shift, B-maximum of upwards shift, beginning of lateralwards shifts at the distolateral angles and of downwards shift in the proximal regions; C-lateralwards shifts at distolateral angles, D-beginning of next downwards phase. Arrows indicate the directions of successive shifts. In $\mathrm{C}$ and $\mathrm{D}$, the external ends of ectodermal cells are shifted distally. Note a pronounced relief of the CR roof in $\mathrm{D}$.

of individual cells during their contraction (according to histological data, the process of cell contraction is practically isometric, i.e. the total cell volume does not considerably change). On the other hand, the described process obviously leads to the ex- 

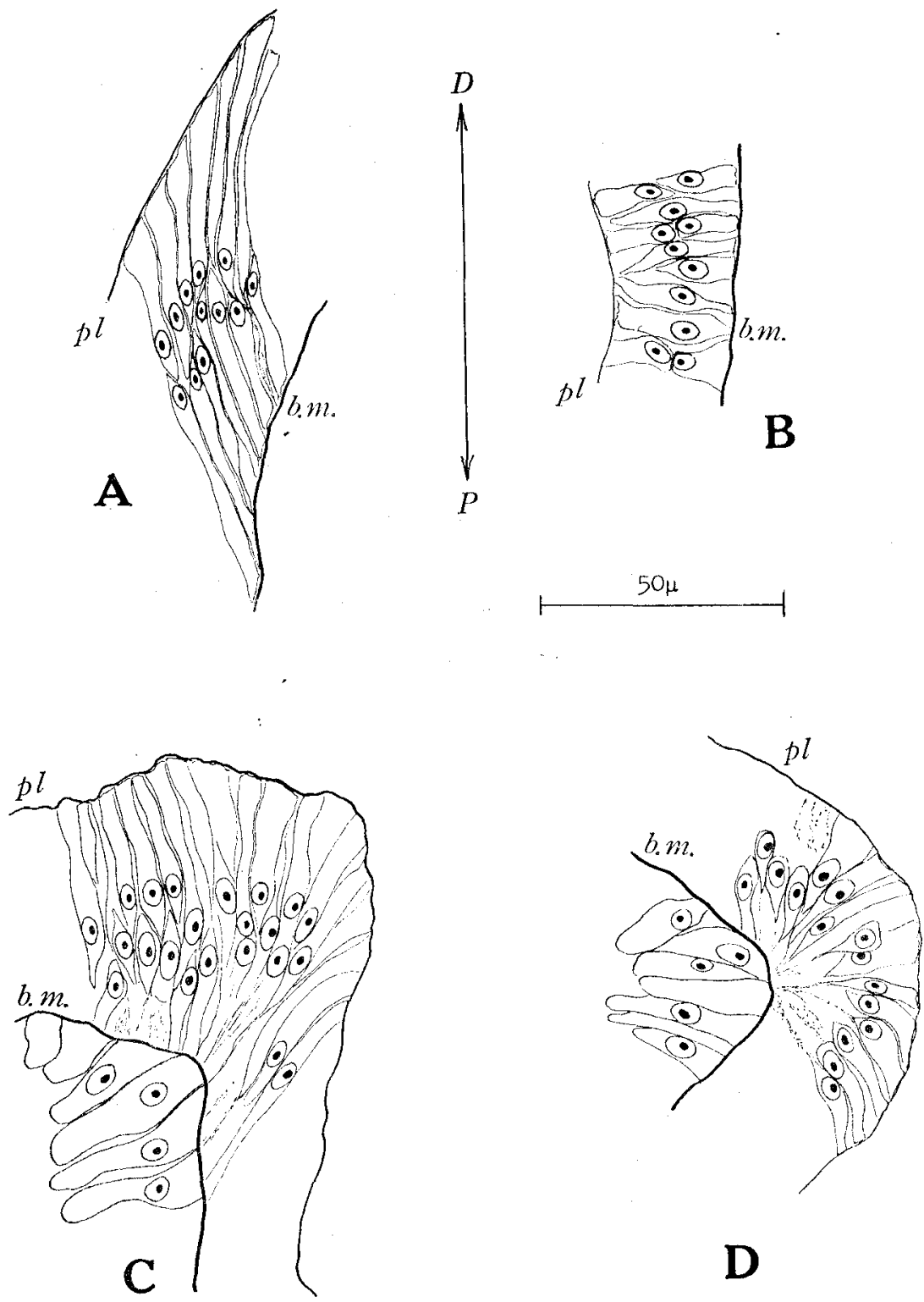

Fig. 27. Details of histological structure of $D$. pumila $C R$ at the opposite phases of growth pulsations. A, B-similar areas of the lateral ectodermal wall of CR respectively during down- and upwards phases; (compare with Fig. 25, A, B). C, D-distolateral angles respectively during retraction and outwards shift (compare with Fig. 26, D, C). Note cell contraction in $B, D$ and their extension in $A, C$. pl-plasmalemma, b.m.-basal membrane. Disto-proximal direction is indicated by DP. 
tension of the whole given area during the cell contraction. Similar process of the intense contraction-repacking of ectodermal tip cells, also leading to the expansion of the whole roof, takes place in $O$. loveni during the transformation of a stem tip to hydranth rudiment (comparing Figs. 25,A,C, and E, one can see the total decrease of cell density in the rudiments roof approximately by 4 times).

In entoderm the processes of cell normalization-denormalization are also well expressed, whereas those of cell contraction and gliding-repacking are less pronounced.

2.2.4.2.2. Micropicture of Shaping Pulsations.

The analysis of short (1-5 min) time-lapse films led to the conclusion that each periodical "outward push" lasts for around $1 \mathrm{~min}$, is $5 \mu$ (Dynamena) or 1-2 $\mu$ (Obelia) in amplitude and regularly takes place around $1 \mathrm{~min}$ (Obelia) or 1.5-3 min (Dynamena, see Figs. 24,C and D) later than each successive upwards wave reaches the level of $a$ given protuberance. A correlation between the spreading of the upwards wave and the growth of protuberances is especially clear in Obelia, in which during each growth pulsation an outwards shift of a distolateral protuberance (Fig. 22,C, dl.p.) precedes that of a tip protuberance (Fig. 22 C,t.p.) just by the time required for an upwards wave to pass the distance between the protuberances (about $1 \mathrm{~min}$ ). According to histological data, cell behaviour during shaping pulsations is similar to that during longitudinal ones. Namely, at the moment of outwards shift (Fig. 27,D) the cells contract, become triangular (this coincides with the results of separation experiments; see 2.2.3.1.) and their density decreases, whereas during the retraction phase they elongate (Fig. 27,C). Note also the relative stability of all protuberances and evaginations during the downwards (retraction) phase (Fig. 26,D).

2.2.4.2.3. Correlation of Growth Pulsations in Adjacent Walls of $\mathrm{C}$ and LRs.

In 38 out of 50 successive pulsations traced in not yet diverged $C$ and LRs of $D$. pumila, an upwards shift of b.m. in CR wall clearly coincided with the downwards shift of b.m. in the adjacent LR wall, and vice versa. The both adjoining walls swung during each pulsation medialwards and lateralwards alternately. The whole process resembles rope pulling by two persons. Indeed, the mechanical principle seems to be just the same. Due to continuity of b.m. between the both rudiments an upwards shift in one of them clearly prevents the shift to the same direction in the other. The most advantageous regime for the both would obviously be a counterphase pulsation. Morphogenetic consequences of such situation will be analyzed below (3.3.).

2.2.4.3. Interpretation of Mechanisms, Underlying Growth Pulsations.

2.2.4.3.1. Mechanisms of Cell Shifts, Underlying Longitudinal Pulsations.

Active Forces. First of all, it is to be decided what kind of contractile system of hydrozoan-myofibrillar (situated in the plane of b.m.) or tonofibrillar (belonging to individual cells) plays a leading role in contraction-normalization processes.

An assumption of the leading role of myofibrillar system seems hardly probable from the very beginning. Even if no attention is paid to HALE's statement about the absence of myofibrills in the growing regions of hydrozoan body (2.2.2.1.), it is quite 
difficult to imagine the mode of action (and, particularly, the points of fixation) of the postulated myofibrills in the process of upwards shift of b.m. Moreover, if it is assumed that the only leading force acts in the plane of b.m., it would be expected that the orientation of adjacent ecto- and entodermal cells is always symmetrical in respect to b.m. Namely, if at a certain moment ectodermal cells are oriented downwards by the ends, adjacent to b.m., the same is to be true for the adjacent entodermal cells, and vice versa.

Really, however, just the opposite takes place; in a majority of cases cells of the both layers are oriented parallel to one another, but not symmetrically in respect to b.m.

At the same time it seems highly probable to ascribe the transversal contractions of the proximal zone to myofibrills, but it must be remembered that no direct correlation was observed between these pulsations and those of distal parts.

Now let us analyze the capacities of tonofibrillar contractions, whose morphogenetic role have been already demonstrated in separation experiments. (2.2.3.1.). It is immediately clear that they can contract the cells, but it is not evident without special comments, whether they can lead to the normalization of cell orientation.

However, it is easy to demonstrate that the latter result would be quite natural if it is assumed that the cells are densely packed and mechanically press one anotherthis seems highly probable for growing zones particularly. Let us regard a group of such cells, being initially oriented obliquely (parallelogramm-like) (Fig. 28). According to histological data, cell volumes do not alter considerably during their contractionextension (isometricity). It is easy to see that the only way to decrease their length (i.e. to contract to some extent) without altering at the same time their volumes (resp.

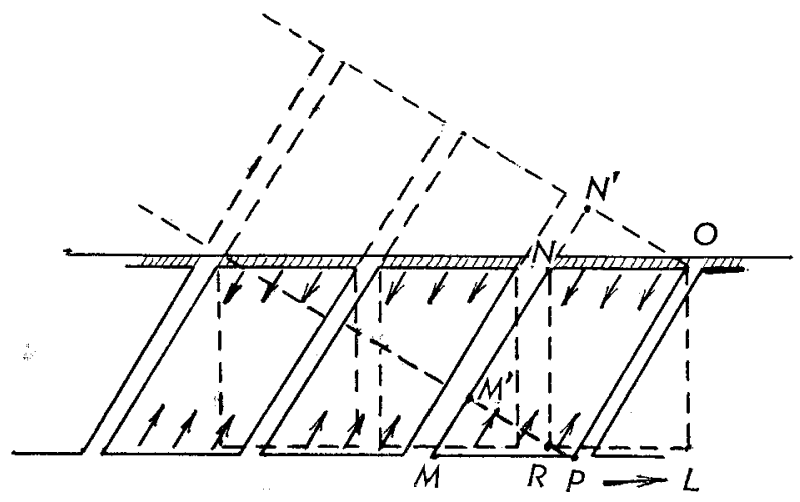

Fig. 28. A theoretical scheme of different ways of normalization of initially parallelogrammic cells. Solid lines--initial cell positions, dotted lines - their positions after contraction (the latter is indicated by three pairs of arrows inside each cell). Arrow $\mathbf{P} \rightarrow \mathbf{L}$ indicates a direction of a shift of the lower surface of the layer, when any turning of the layer is prevented. 
squares) and without increasing their diameters (this is prevented by the pressure of neighbouring cells) is to transform their shape towards rectangular one. Indeed, in contraction (Fig. 28), $\mathrm{OL}<\mathrm{OP}$, while $\mathrm{S}_{\mathrm{MNOP}}=\mathrm{S}_{\mathrm{LRNO}}$ (isometricity) and $\mathrm{MP}=\mathrm{RL}$ (constancy of diameter).

One can see that the transformation of cell shape from parallelogram towards rectangle can be reached by the following two ways: 1 by tangential shift of the both layer surfaces in opposite directions, or by the shift of one surface in respect to the other fixed one (Fig. 28, arrow $\mathrm{P} \rightarrow \mathrm{L}$ ) $; 2$ by turning of a given part of the layer as a whole (Fig. $28 \mathrm{M} \rightarrow \mathrm{M}^{\prime}, \mathbf{N} \rightarrow \mathrm{N}^{\prime}$,), this means the deformation of the whole rudiment, to which a given part of the layer belongs.

It is clear that the intermediate ways are as well possible, and that the choice between these two possibilities depends upon the character of the layer's fixation. The first way would be natural for those stem areas which are in contact with the rigid perisarc which is preventing or at least hampering any attempts of lateralwards shifts, but serving as a fixing surface for the linear shifts. On the other hand, the tip areas covered with the soft, newly deposited perisarc, have more possibilities for deformations. Some other situations, also favourable for deformations, will be discussed later. Anyhow, the above-said demonstrates obviously the possibility of cell normalization, and thus of the upwards b.m. shift as a result of tonofibrillar contraction. As to the downwards shift, it coincides, according to the above-said, with cell elongation (relaxation) and is obviously due to passive recurrence of b.m.

Passive Forces and Supporting Structures. In order to lead to the progressive stem growth, the contracted-normalized cells must possess some supporting structures and be the object of action of some passive (elastic) forces.

First of all, to shift b.m. and stem tip upwards but at the same time not to shift plasmalemma downwards, cells must have a support somewhere below the tip. Obviously, a supporting role is played by hydrotheca (Fig. 23, A and B, dotted area). This assumption does not require any specific mechanisms of cell-hydrotheca or plasmalemma-hydrotheca connections, since the very expansion of coenosarc during the cell contraction as well as some architectural features of hydrotheca (successive transversal grooves) promote a closer contact and, thus, a considerable friction between the both structures. The next important point is that as a result of cell contractions, plasmalemma is stretched and, thus, accumulates certain elastic energy. The conditions for its release seem to appear later, namely at downwards phase. At that time, due to cell relaxation (and, thus, to decrease of coenosarc diameter) plasmalemma detaches from hydrotheca, but remains at the stem tip (where new hydrotheca is constantly deposited; see 2.2.2.1.) (Fig. $23 \mathrm{C}$ and $\mathrm{D}$, dotted area) closely connected with it. In such conditions the elastic contraction of previously stretched plasmalemma pulls upwards the external cell ends. The fact that such shifts are taking place not at every growth pulsation are compatible with the assumption that a considerable degree of plasmalemma stretching is to be reached in order to achieve a sufficient elastic 
pulling force.

The last point to be interpreted is why in the downwards phase the reverse shift of stem tip is smaller than its upwards shift. Besides the rigidity of even newly deposited hydrotheca, it seems to be determined by the common "crush-resistance" of arched structures (see 2.2.2.1.).

Therefore, we assume that besides the active force of cell contraction a passive force of elastic plasmalemma contraction plays a necessary role in progressive growth. Next, it is suggested that fixing points are shifted during each growth pulsation: whereas in the upwards phase the supporting role is played by subapical hydrotheca, in the downwards phase it is played by an apical one (compare localization of dotted areas in Fig. 23 A,B and C,D).

This description was related mainly to ectoderm. As to entoderm, its capacity of autonomous upwards shifting remains not quite clear; it seems probable, however, that it behaves in a similar way and the role of stretched elastic membrane is played by b.m.

2.2.4.3.2. Mechanisms of "Shaping Pulsations".

A simple regularity can be easily formulated as a result of film analysis: the pulsatory shifts, leading to shape alterations, are taking place only at those points of rudiment surface, whose initial local curvature has been already greater than that of surrounding ones. The result seems to be quite natural if it is taken into account that each outwards "shaping shift" coincides with the contraction of cells of this very area. The following analysis will demonstrate the importance of the initial geometry of a surface for its successive shape alterations.

Let us regard (Fig. 29) an area of irregular curvature (curvature of area 4-8 is greater than that of peripheral zones), composed of normally oriented and densely packed cells $1-11$. If all cells contract simultaneously and to the same extent along

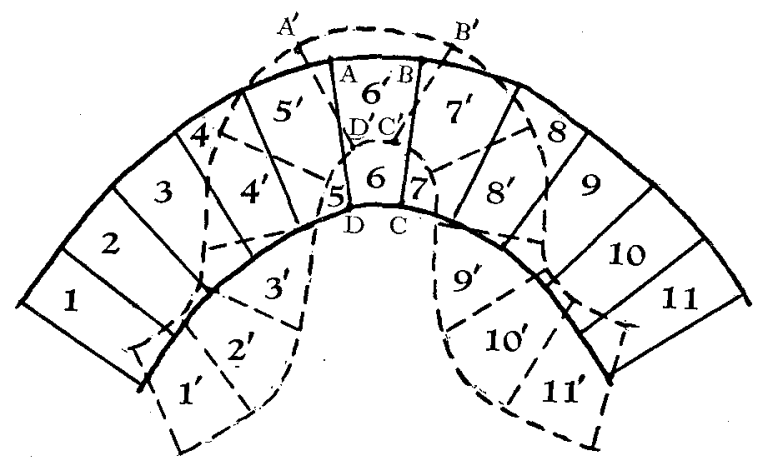

Fig. 29. A scheme of deformation of a layer, composed of densely packed contracting cells. $1-11$ - initial positions, $1^{\prime}-11^{\prime}$ - final positions of the same cells. An initial curvature of an area $4-8$ is assumed to be much more than that of lateral areas 1-3 and 9-11, this results in the opposite folding of the central and peripheral areas. 
their axes (i.e., normally to the local surface of a layer), keeping the constancy of their volumes, they will obviously "push" one another in lateral directions, and increase their transversal surfaces (when cell 6 transforms to $6^{\prime}, A^{\prime} B^{\prime}+C^{\prime} D^{\prime}>A B+C D$ ).

It is easy to see that this will lead to the further increase of curvature, the increase being approximately proportional to the initial curvature. ${ }^{6)}$ (The important exceptions are the cases of very high local curvature in sharp outgrowths; cells, situated at their tips, are shifted in relation to its neighbours and cannot sufficiently press them. This may be a "self-restriction" factor of growth of very sharp evaginations). Therefore, the curvature of the area 4-8 predominantly increases.

Moreover, if an initial curvature of the central area 4-8 was much greater than that of peripheral (linear or circular) areas 1-3 and 9-11, the latter cells would be pushed in the opposite direction $\left(2 \rightarrow 2^{\prime}, 10 \rightarrow 10^{\prime}\right)$ in relation to the central cell group. Thus, a central evagination will be limited by linear or circular groove(s), and the arising shape of a layer will be more "complex" than the initial one.

It is easy to see that the above-said is no more than the generalized account of the processes of rapid outwards pushes, either in normal development of protuberances or in dissected rudiments. The only important distinction is that the formal picture is more deterministic than the real one; in reality, the directions of cell shifts are correlated with the local curvature only statistically, as one can see from Figs. 18 and $27, \mathrm{C}$.

\section{General Interpretation of Hydrozoan Morphogenesis}

In the previous section some general modes of behaviour of densely packed contractile cells were analyzed. It was concluded that in such systems the processes, similar to the observed ones, were quite natural and did not require any complicated additional assumptions. Now an attempt will be made to demonstrate that a great majority, if not all, of essential morphogenetic processes in hydroids may be also regarded as simple consequences of the properties of such systems, namely, of the layers, composed of contractile cells, densely packed and closely attached to the layer surfaces.

Three properties of such systems, which are of primary importance for interpretation of morphogenesis, will be now formulated. They will partly repeat the above said and will not require almost any additional comments.

3.1. Some Morphogenetically Important Types of Cell Behaviour.

(a) If a given area of a rudiment is of irregular curvature, that is, if it is not a part of sphere or flat surface, the local differences in curvature will increase in such a way that in certain boundaries the rate of curvature increase will be approximately proportional to the initial curvature. It has been already demonstrated that this will lead to the arising of shape complexity of a given area, i.e. to its successive differen-

6) This is true of course only if there is a resistance to the layers stretching from the adjacent parts of coenosare and hydrotheca. 
tiation to an increasing number of in- and evaginations (2.2.4.3.2., Fig. 29).

(b) If cells of contralateral walls of a rudiment are situated asymmetrically and there exists a force preventing their symmetrization, the wall with more oblique orientation will be stretched more rapidly than the opposite wall. If at the same time the roof of the rudiment is non-expansible, the rudiment as a whole will bend, its "oblique" wall becoming convex.

Here some comments are needed.

We have already seen, indeed, that the contraction of tonofibrills of the obliquely oriented cells leads to upwards shift of its basal membrane, i.e. to the shift of certain amount of cell material. The less oblique is initial cell orientation, the smaller would be the length of the upwards shift per growth cycle. This leads to the asymmetry of growth of the rudiments with asymmetrical cell orientation.

(c) According to the above-said, if cells are oriented abnormally (obliquely) to the layer surfaces, the immediate result of their contraction will be normalization of their orientation in relation to the layer surfaces, leading either to the shifts of the opposite layer surfaces in the opposite directions, to the turning of a layer as a whole, or to an intermediate result. As it has been already mentioned, the choice between these possibilities depends upon the character of layer fixation and of the external mechanical resistances; e.g. the existence of a rigid hydrotheca favours the first possibility. Now some other conditions are to be analyzed. Namely, one may demonstrate that the contraction of reversed cells, composing a proximal part of developing hydranth and CR (2.2.2.3.2.) leads to the turning of the layer. Indeed, the shifting component of normalization process in these cells counteracts with the oppositely directed shifting tendencies in non-reversed cells of the more proximal areas. At the same time there are no mechanical obstacles to the deformation of a layer. In such a situation, a "deforming component" is obviously much more expressed than the shifting one, this leads to the contraction of hydranth neck. In addition, however, some signs of counteraction of the opposite shifting tendencies are visible; they will be analyzed later.

The readers will see that (b) and (c) give a causal interpretation to the cases of "prognostical orientation", which were described above (2.2.2.3.1.; 2.2.2.3.2.).

Let us now demonstrate that the above properties are sufficient for complete interpretation of the vegetal morphogenesis of Hydrozoa.

3.2. Interpretation of Vegetal Morphogenesis of $O$. LOVENI (see 2.2.1.1.)

3.2.1. Why Daughter Stem (d.s.) is Initiated at the Convex Side of the Maternal One and is Bended on the Same Plane as the Maternal One?

The initiation of daughter evagination at the convex side of the maternal stem and its separation by circular groove is directly deduced from 3.1.a. The direction of its growth in respect to the maternal stem is determined by its cell orientation and by intensive upwards shifts, characteristic of the convex side of rudiments (3.1.b.). As a result, d.s. forms a sharp angle with the maternal one and the depression, separating 
d.s. from the distal side (Fig. 5, dst.d.), becomes narrower and deeper than that on the proximal side (Fig. 5, pr.d.). Therefore (3.1.a) at the early stages of d.s. growth the rate of deepening of the distal groove will exceed that of proximal one, whereas later the distal groove will become so sharp that the "deepening force" in its tip ceases (2.2.4.3.2.) and then the only one remaining force is that localized at the tip of the proximal groove.

Each "deepening force" evidently alters cell orientation in the lateral walls of an evagination (note that in Fig. 29 not only the shifts, but as well the reorientations of cells $5 \rightarrow 5^{\prime}, 4 \rightarrow 4^{\prime}$, etc., are taking place). Therefore, a period of predominance of the distal deepening force leads to the turning of d.s. towards the maternal one, whereas a period of predominance of the proximal deepening force leads to the lateralwards bending of d.s.

The existence of the antagonistic turning forces was directly demonstrated in separation experiments (2.2.3.1.). So far as the turning forces are transmitted to the growing tip throughout the whole densely packed cell sheet, the "prognostical" asymmetry of cell orientation between the contralateral walls inevitably arises, also reflecting the asymmetry of turning forces.

3.2.2. General Character of the Stem Growth. Initiation of Hydranth.

It has been already mentioned (2.2.4.1.) that during the intensive stem growth its tip ectoderm is relatively high, while at the beginning of hydranth formation it becomes lower (in other words, the distance between plasmalemma and b.m. decreases). Let us now demonstrate that this simple alteration can effectively "switch" the whole course of development from stem elongation to hydranth differentiation.

Due to the approximately hemispherical form of the stem tip the contraction of its cells inevitably leads to its regular expansion and to its partial separation ("Durchschnurung" of German authors) from more proximal regions (3.1.a). For purely geometrical reasons the expansion tendency is common for different tip regions inspite of their detailed structure. It is obvious, however, that when the entodermal cellular hemisphere is situated considerably below the stem tip (and, thus, from the ectodermal cellular hemisphere), the maximal expansion forces of these two hemispheres are applied at different levels (considerably subapical for the entodermal one). This correlates with the typical subapical broadening of the elongating stem.

On the contrary, if the both layers are "packed" more closely (this is a specific prerequisite of hydranth initiation), their maximal expansion tendencies are drawing together and to the stem tip, this results in the intensive of the apical region, i.e. to hydranth initiation. ${ }^{7}$

What can be the causes of this "pre-hydranth" approach of the both layers? Clearly, it is not strictly determined either in space or in time, so far as the length and

7) It should be remembered in this respect that in scyphozoan gastrulae the relative distance between the both layers seems to be the main factor determining whether scyphystoma or medusa will be developed (BerRILL, 1960). 
duration of the stem growth before hydranth initiation can considerably vary. The most natural cause, which is obviously of a stochastic nature, is the marked difference in proliferative activity of ento- and ectoderm of tip regions (2.2.2.2.1.). So far as ectodermal tip cells do not almost proliferate, whereas those of entoderm are actively dividing, the cell density of ectoderm in the apical regions will gradually decrease, leading to the decrease of the rate of upwards shifting of ectoderm as comparing with entoderm.

3.2.3. Morphological Differentiation of Hydranth.

Let us employ now (3.1. a) for the more detailed analysis of geometrical transformations of a hemispherical surface, conjoining with the cylindrical one, which is a fairly good approximation of configuration of initiation of hydranth (Fig. 30, 1-1). To reflect the assumed proportionality of the shifting rates to the local curvatures, several points (representing the areas of different curvatures) are to be taken on the surface (e.g., Fig. 30, a,b,c) and the outwards vectors directed normally to the successive surfaces are to be plotted at every point. The vector values are to be proportional to local curvatures. The contour, conjoining the ends of vectors (2-2-2), is to be regarded as a theoretical construction of the next developmental stage. The whole construction should be repeated several times (3-3-3, 4-4-4, etc.). According to initial assumptions of the method, the less are the successive "steps" (i.e., vector values), the more precise will be the theoretical configuration. It is clear as well that very slight initial differences of curvatures at points $a$ and $b$ may lead to the formation of a protuberance

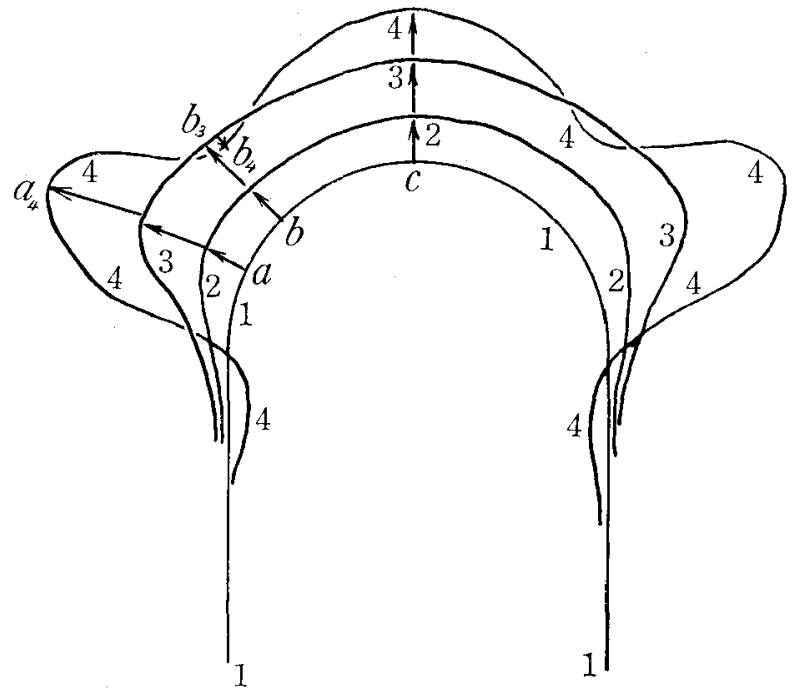

A

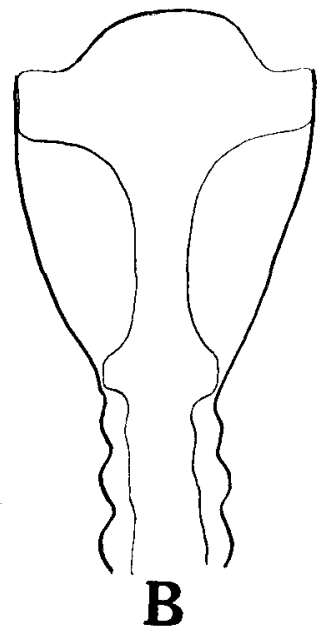

Fig. 30. A simplified theoretical construction of morphogenesis of Obelia hydranth (A), as compared with its real shape (B). 1-1-1-approximation of the initial configuration; 2-2-2, 3-3-3, 4-4-4 successive steps of theoretical construction. 
around $a_{4}$ and to the inwards movement $b_{3}-b_{4}$, leading to the formation of a depression. As a result, a series of configurations thus obtained is evidently similar to the successive stages of normal hydranth development. The neck, common tentacle rudiment and the hypostome protuberance are thus reproduced (compare Fig. 30, $\mathrm{A}$ and $\mathrm{B}$ ).

It can be demonstrated as well that a considerable expansion of a rudiment leads automatically to the reversion of cell orientation in its lateral walls. Indeed, the cells of disto-lateral angles, when contracting, intensively pull the b.m. upwards and decrease at the same time the upwards tension of plasmalemma, this naturally leads to the reversion of proximally localized cells.

The results of tonofibrillar contractions of reversed cells have been already discussed. Two components of the process are to be distinguished: (a) turning, i.e. deformation of the whole sheet, (b) proximalwards shift of b.m. The first one promotes the formation of the narrow neck, the second one counteracts the oppositely directed shift of more proximal cells. The natural result of the counteraction is the increase of the internal mechanical pressure at the circumference of counteracting zone, bringing about outward "squeezing" of cells of this zone. It is highly remarkable that the narrow circular outgrowth of diaphragm arises at the very zone of the meeting of the opposite cell orientations. Evidently, such may be the mechanism of diaphragm formation.

\subsection{Interpretaion of Specific Properties of Vegetal Morphogenesis of} D. PUMILA.

A number of features of $D$. pumila morphogenesis, especially the general character of growth and differentiation of CR, are qualitatively similar to those of $O$. loveni and do not require further analysis. In this section only those processes will be discussed, which are specific to $D$. pumila. It will be demonstrated that they are mainly determined by interactions between CR and LRs.

1. Why in normal conditions LRs bend laterally, while CR is growing straightly upwards?

The directions of rudiments growth can be directly deduced, according to $3.1 \mathrm{~b}$, from cell orientation in the rudiments. The latter, in its turn, is to be regarded, on one hand, as a result of intrinsic "normalization" tendency in "free" walls (i.e., the lateral walls of LRs) and on the other hand, as a result of the influence of the neighbouring rudiments, preventing normalization in the adjacent walls. The mechanics of such "denormalizing" influences is directly derived from the fact that C and LR oscillate mainly in counterphase (2.2.4.2.3). Indeed, in such situation each downwards shift in each rudiment would be reinforced by the coincident upwards shift in the adjacent rudiment (effect of "rope pulling"). Therefore, each downwards shift would be greater than in the absence of neighbouring rudiment and, thus, cell orientation in the maximal downwards phase would be more oblique (in reality, cells are oriented at that moment almost parallel to the layer surface). According to 3.1. b, in such situation a 
major part of cell contraction force is "canalyzed" longitudinally, thus promoting an upwards growth of a given part. (Note that each upwards shift in each rudiment is in no way prevented by the neighbouring rudiment because it coincides mainly with the downwards (relaxation) phase of the latter). It is completely clear as well that the removing of a rudiment or breaking of material connections between the adjacent rudiments (2.2.2.4.) ceases these mutual "denormalizing" influences, this leads to rapid normalization of cell orientation and to the corresponding alterations of growth directions.

2. Why does CR expand only on frontal, but not on the saggital plane?

Let us analyse the factors, determining cell orientation in "saggital" (free, not adjoining to LRs) and in "frontal" (in contact with LRs) walls of CR. Nothing prevents the first ones to orient normally, whereas the last ones are forced to orient obliquely. Now, according to 3.1 . b, the more cell orientation deviates from the normal one, the greater is the upwards shift per each growth pulsation, Hence, the frontal walls have to elongate more rapidly than the saggital ones. The morphogenetic result of such disproportion would depend upon the external conditions of CR growth. As long as the CR remains in close contact with LRs, the latter prevents the expansion of the former which is, then, allowed only to elongate. In this situation the described correlation would evidently lead only to the depression of the CRs roof on the sagittal plane. When, however, LRs lose their contact with the central one and bend lateralwards, the mechanical hindrances to CR expansion will disappear. Also employing 3.1. $b$, one easily see that normalizing tendencies of cells of frontal walls lead to expansion of CR (see the "prognostical" construction, Fig. 15).

3. Why is CR divided into three parts?

It is impossible to derive from the above purely qualitative rules the exact number of parts into which a rudiment of a given shape is to be finally separated. However, the following tendencies may be deduced: each elongated rudiment tends to subdivide perpendicularly to the direction of its extension, the number of metameres increases with the increase of the ratio length/width $\left(\frac{l}{w}\right)$, and the dimensions of the extreme metameres are more stable than those of the central one(s).

To demonstrate this result (for its more refined mathematical deduction from similar postulates, see BELOUSOV and DORFMAN, 1972), the same construction, as in the case of Obelia hydranth differentiation, may be used. One can see that the same tendencies of increasing the local curvature lead in this case to the subdivision of the rudiment into three parts, the lateral ones corresponding to the LRs, whereas the central one to the CR (Fig. 31,A). The less were the ratio $\left(\frac{l}{w}\right)$, the narrower would be the central segment, and vise versa. Obviously if the ratio drops below a certain threshold value a central segment will completely reduces. Analysis of the structure of $D$. pumila colonies of different ages clearly demonstrates the existence of such 

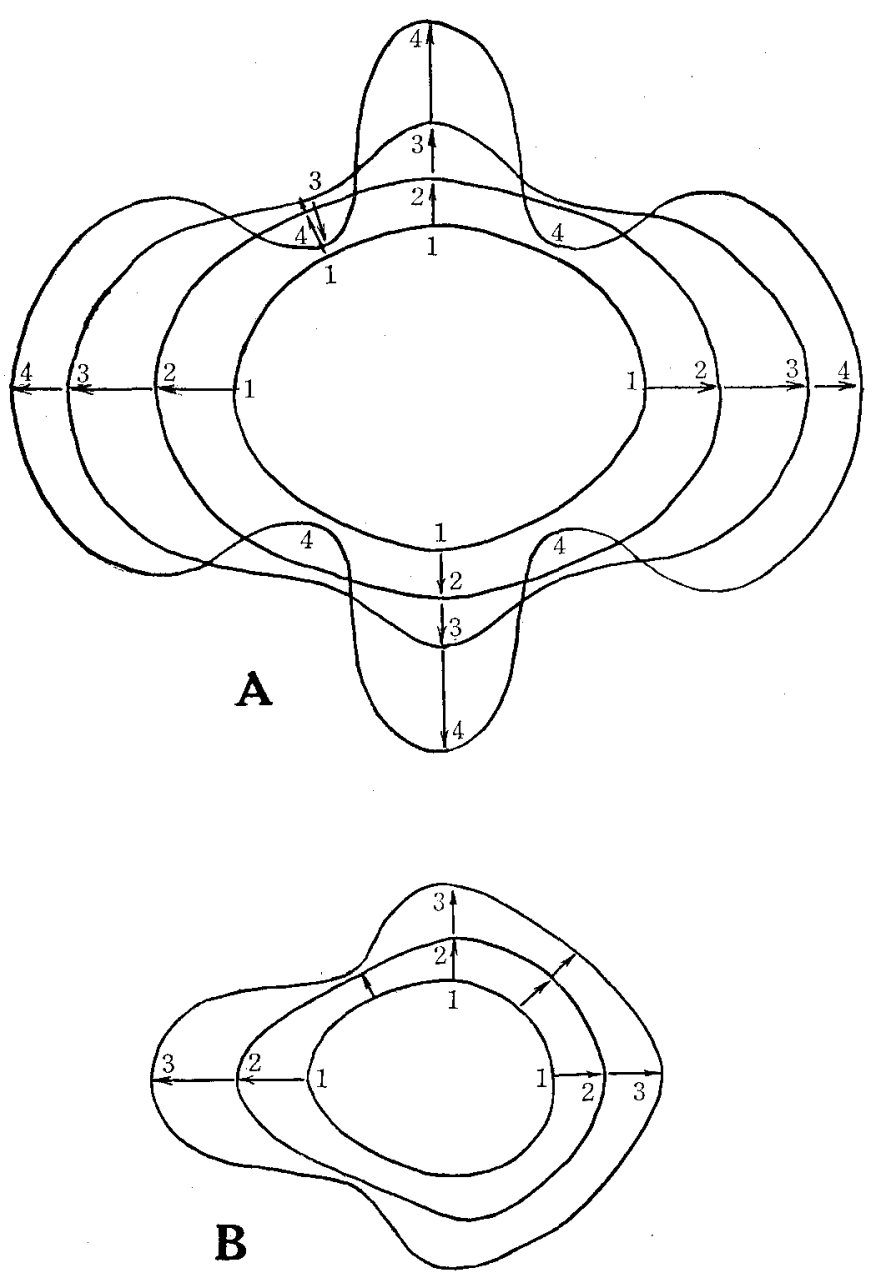

Fig. 31. Theoretical constructions of some processes of D. pumila morphogenesis (transverse sections). A-successive stages (1-4) of subdivision of an initially smooth $\mathrm{CR}$ to three parts. B successive stages (1-3) of subdivision of a young $D$. pumila stem. The initial configuration is similar to Fig. 32, A.

situation. Namely, if $\frac{l}{w} \geqslant 2$, the rudiments will subdivide into three parts (Fig. 32,F), but when $\frac{l}{w} \sim 1.3$ (what is typical for young colonies and for some abnormal ones), they are subdivided only into two parts (Fig. 31,B; Fig. 32,B,H). Sometimes the crosssections of young eolonies are approximately triangular (Fig. 32,C). Then a typical "trefoil" subdivision occurs, which also can be easily derived from the rule (1) (Fig. $32, \mathrm{D})$. 
<smiles>CP(C)(C)(C)C(F)(F)F</smiles>
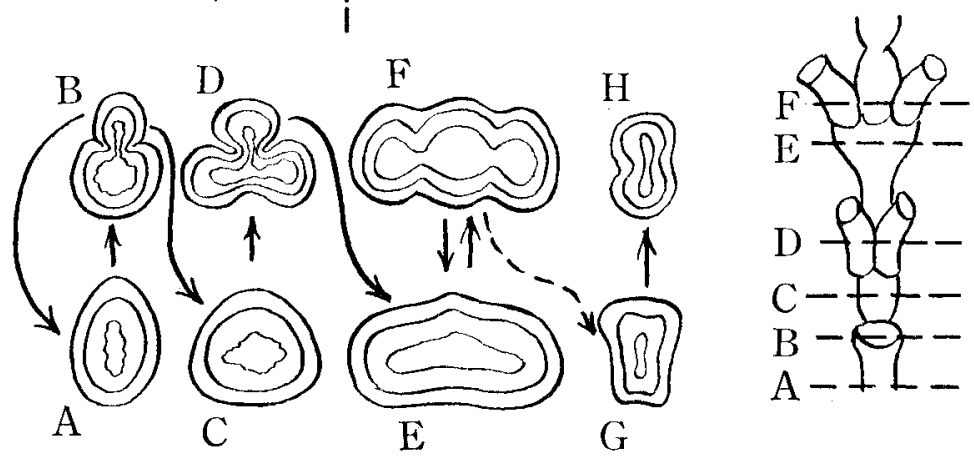

Fig. 32. Schematical drawings of a series of transverse sections of a normal D. pumila colony, arranged in proximo-distal direction (A-F), aberrant variants in crosssections (G-H) and on the right the lateral view of a colony with the indications of levels corresponding to the drawings A-F. At the top, sagittal and frontal planes are indicated. A-F present at the same time the successive stages of development of a colony. The forms B, D, F, H may be directly derived from the forms A, C, $\mathrm{E}, \mathrm{G}$ correspondingly by means of the rule 3.1.a. (From Belousov and Dorfman. 1972, modified).

\subsection{CONCluding Remarks.}

The main aim of this paper was to demonstrate that a wide range of morphogenetic processes in Hydrozoa could be deduced from fairly simple and homogeneous behavioural characteristics of individual cells, namely from their capacity to periodical contractions-extensions. No specific differences between the cells were introduced at any moment of our interpretation, this seems to us to be its important advantage. The only factors, which integrate cell behaviour in the whole rudiments, were assumed to be the shape of cell sheet (distribution of local curvatures) and some sort of not very strict temporal organization of cell behaviour (approximate synchronism of their contraction, proximo-distal spreading of relaxation impulses).

We wish to stress as well that at least in studied species very simple, obviously purely mechanical factors can play a leading polarizing role in early embryonic development.

Needless to say that the above simple principles may promote the interpretation only of "developmental geometry" of the studied species and no attempt was made here to analyse much more complex processes of the internal cell differentiation. However, it is to be remembered that at least in the case of planula development the pattern of biochemical differentiation can be, in the long run, completely determined by initially mechanical factors (Belousov and Ostroumova, 1969; Ostroumova and Belousov, 1971). Similar correlations can take place in other differentiation processes. 
Several points, belonging more closely to the topics of the paper, also remain unclear. Further studies, perhaps physiological and particularly electrophysiological, are undoubtedly required to reveal the mechanisms of arising and spreading of contraction-relaxation impulses. The only aspects, which are still to be briefly discussed here, are related with the problem of geometrical organization:

3.4.1. What Determines the Moment of Ceasing of Morphogenetic Movements in Developing Rudiments?

Some of the described developmental processes, e.g. the branching in Obelia and Dynamena colonies, can be regarded as theoretically interminable (cyclic). Its ceasing is obviously determined by external factors, such as temperature conditions, exhausting of food supplies, inhibitory activity of other parts of colony, etc.

In hydranth rudiments, however, a moment of growth and morphogenesis arrest is determined more strictly. In other words, to avoid any absurd results, a number of successive steps of theoretical constructions (Figs. 31 and 32) are to be limited. What may be the basis of such limitation?

According to our data, one of the main limiting factors can be the decrease of cell density, always taking place in the proximal parts of hydranth, in its roof and in other regions. It is of interest in this respect that in the distal half of hydranth rudiment, where the cells are continuously densely packed and oriented normally to the surface, a continuous folding takes place even after the whole rudiment stopped to grow. As a result, the circumference of a rudiment splits into small metameres, each of them transforming later to a tentacle. Such progressive folding is a natural result of the prolonged action of 3.1.a. Therefore, ceasing of growth and morphogenesis seems to be determined not by any generalized factor, but, mainly, by local conditions in a given region, in which cell density plays an important role.

3.4.2. On Species Specificity of Morphogenesis.

The problem of species specificity of morphogenesis of studied species is in no way exhausted by the previous comparison between Obelia and Dynamena developments. Even those morphogenetic processes, which have been claimed to proceed in similar ways (e.g. differentiation of Obelia hydranth and $D$. pumila $\mathrm{CR}$ ), are not at all identical, but, so to say, only to a large extent homologous, or homeomorphic. They possess, at the same time, some important quantitative differences. For example, in $D$. pumila all the grooves and depressions are much deeper and sharper than in $O$. loveni.

On the other hand, our analysis of specific features of $D$. pumila development started from the stage, when a certain rudiment had been already subdivided into three parts. What was deduced from the above rules, was, generally, only the maintenance of the same expansion (resp. subdivision) plane in a series of successive generations of CRs. The problem, however, remains unsolved, why the tip of the primary hydranth or of the young stem of $D$. pumila, initially not far from spherical shape, invariably becomes ellipsoidal, whereas that of $O$. loveni remains almost spherical. What kind of alterations in genetic programms may lead to such differences? In 
our opinion, a hypothesis is to be proved that there are some important mechanical and energetical properties of cells and/or surface membranes of epithelial sheets (rigidity, plasticity, firmness of cell contacts, energy of contraction, etc.) to be genetically determined (thus, species-specific), whereas the general morphogenetic properties (3.1.a-c) remain invariable. Hydroid polyps (especially Sertulariidae) are quite suitable objects for such investigations, because they combine a far-going homeomorphism of structure with the visible geometrical species-specific differences.

\section{Summary}

1. Morphological polarization of Clava multicornis and Obelia loveni embryos is described. At the morula stage the direction of antero-posterior axis is not yet irreversibly determined. It can be reoriented by means of mechanical pressure. There is no direct correspondence between the vector of animal-vegetal polarity or of primary metabolic gradients and that of morphological axis. The elongation of planula is determined by unequal distribution of mitotic activity.

2. There is no direct correspondence between the shape and/or growth rate of vegetal rudiments of studied thecaphoran species and the localization, intensity and orientation of cell divisions.

3. Alterations in cell orientation in bending outgrowths and developing hydranths precede in a regular way the alterations in growth directions and/or shape of the rudiments. In $D$. pumila, cell orientation and the direction of rudiment growth are determined by the presence of adjacent rudiments.

4. Separation of different parts of developing rudiments leads to rapid alterations of their shape similar to those taking place during their normal development. This demonstrates the existence of morphogenetically important mechanical stresses, obviously caused by tonofibrillar contraction. A partial reversion of rudiment shape after inhibition of its metabolism demonstrates the mechanical non-equilibricity of rudiment shape.

5. Using time-lapse cinematography, the pulsatory character of growth and shaping was revealed. Growth pulsations are the external expression of periodical contractions-extensions (resp. reorientations) of myoepithelial cells in the both germ layers. Almost synchronous cell contraction and proximo-distal waves of cell extension were observed.

6. Linear growth of rudiments is a result of alternating distalwards shiftings of basal membrane and plasmalemma. The shiftings are obviously determined by active tonofibrillar contractions of myoepithelial cells and by passive elastic contraction of plasmalemma. Subapical and apical hydrotheca serves alternatively as a surface of fixation.

7. Shaping of rudiments is a result of regularly distributed outwards and inwards cell shifts, determined by a mutual mechanical pressure of densely packed and peri- 
odically contracting cells. In such systems the initial curvature of cell layer and cell orientation in it must play a leading morphogenetic role. A number of morphogenetic processes in $O$. loveni and $D$. pumila is modelled on the basis of these assumptions.

\section{Acknowledgements}

I am greatly indebted to Dr. T. V. Ostroumova, whose experimental materials on embryonic polarization were used in this review; to Drs. L. A. Badenko, A. L. Katchurin, G. G. PEtrov, and B. G. SAFRONOv for their technical assistance in time-lapse filming; and to Dr. Ja. G. Dorfman for mechanical and mathematical analysis of some aspects of morphogenesis.

\section{REFERENCES}

BeLousov, L. V., 1961a. Vital observations on cell migrations in hydroid Obelia loveni. Dokl. Ak. Nauk SSSR, 136, 1490-1493 (Russ.)

BeLousov, L. V., 1961b. Cell proliferation and growth in hydroid polyps. Zchurn. Obsch. Biol., 22, 281-291 (Russ.).

Belousov, L. V., 1963. An arising of abundant interstitial cells. Dokl. Ak. Nauk SSSR, 150, 690693 (Russ.)

Belousov, L. V., 1965. Alteration of growth direction of rudiments as a result of their interactions. Dokl. Ak. Nauk SSSR, 160, 475-478 (Russ.)

Belousov, L. V., Badenko, L. A., Katchurin, A. L., and Kurilo, L. F., 1972. Cell movements in morphogenesis of hydroid polyps. Jour. Embr. exp. Morph. 27, 317-337.

Belousov, L. V. and Dorfman, Ja. G., 1972. Methematical modelling of some morphogenesis. II. "U-shaped" model. Ontogenes, 3, 144-153 (Russ.)

Belousov, L. V. and Ostroumova, T. V., 1969. Metabolic gradients and morphological polarization in embryonic development of hydroid polyps. Journ. Embr. Exp. Morph. 22, 431-447.

BerriLl, N. J., 1961. Growth, Development and Pattern. N. Y., McGraw-Hill.

Billard, A., 1904. Contribution à 1'étude des Hydroides. Ann. Sci. Natur. Zool., sear. 8, 20.

Campbell, R. D., 1967. Cell proliferation and morphological patterns in the hydroids Tubularia and Hydractinia. Journ. Exp. Zool. 17, 607-616.

Crowell, S., Wyttenbave, Ch. and Suddith, P., 1965. Evidence against the concept of growth zones in hydroids. Biol. Bull. mar. biol. Lab., Woods Hole, 129, 403.

Filatcheva, L. F., 1966. Morphogenesis of lateral outgrowth of hydroid Dynamena pumila. Biologich. Nauki, 1, 7-13 (Russ.)

HALE, L. J., 1960. Contractility and hydroplasmic movements in the hydroid Clytia johnstoni. Q. Journ. micr. Sci. 101, 339-350.

HALE, L. J., 1964. Cell movements, cell division and growth in the hydroid Clytia johnstoni. Journ. Embr. Exp. Morph. 12, 517-538.

MERgner, H., 1971. Cnidaria. In: Experimental Embryology of Marine and Fresh-water Invertebrates, ed. G. Reverberi, North-Holland Publ. Co.

Naumow, D. V., 1960. Hydroids and Hydromedusae. Publ. House of Ac. Sci. USSR, MoscowLeningrad (Russ.).

Ostroumova, T. V., and Belousov, L. V., 1971. Determination of morphological polarity in embryogenesis of hydroid polyps. Zchurn. Obsch. Biol., 32, 323-331 (Russ.).

SAINT-HILAIRE, K. 1930. Morphogenetische Untersuchungen der nichtzellulären Gebilde bei Tieren. Zool. Jahrb. Abt. allg. Zool. u. Physiol., 47, 512-622.

WyttenBaCH, Ch. R., 1968. The dynamics of stolon elongation in the hydroid Campanularia flexuosa. Journ. exp. Zool. 167, 333-353. 